\title{
Methodology for classifying the ecosystem integrity of forests in Germany using quantified indicators
}

\author{
Martin Jenssen \\ Waldkunde Institut Eberswalde \\ Stefan Nickel \\ University of Vechta: Universität Vechta \\ Winfried Schröder ( $\square$ wschroeder@iuw.uni-vechta.de ) \\ CHair of Landscape Ecology https://orcid.org/0000-0002-3743-6495
}

\section{Research}

Keywords: Ecosystem classification, ecosystem functions, ecosystem structures, ecological indicators, environmental monitoring, Geo-information System, mapping

Posted Date: December 18th, 2020

DOl: https://doi.org/10.21203/rs.3.rs-127444/v1

License: @ (i) This work is licensed under a Creative Commons Attribution 4.0 International License. Read Full License

Version of Record: A version of this preprint was published at Environmental Sciences Europe on April 14th, 2021. See the published version at https://doi.org/10.1186/s12302-021-00478-y. 
1 Research Paper

2

3 Title Page

4

$5 \quad$ Methodology for classifying the ecosystem integrity of forests in Germany

6 using quantified indicators

7

8 1Martin Jenssen, ${ }^{2}$ Stefan Nickel, ${ }^{2}$ Winfried Schröder*

9

$10{ }^{1}$ Institute of Forestry Eberswalde, Hohensaatener Dorfstraße 27, 16259 Bad

11 Freienwalde, jenssen.waldinstitut@t-online.de

$12{ }^{2}$ Chair of Landscape Ecology, University of Vechta, P.O.B. 1553, 49364 Vechta,

13 winfried.schroeder@uni-vechta.de,s.nickel@planwerk-nidda.de

14 *Corresponding author

15

16 Abstract 
16.12.2020 10:45:45

18 Background. Atmospheric deposition of nitrogen $(\mathrm{N})$ and climate change can

19 have impacts on ecological structures and functions, and thus on the integrity of

20 ecosystems and their services. Operationalization of ecosystem integrity is still

21 an important desideratum.

22 Results. A methodology for classifying the ecosystem integrity of forests in

23 Germany under the influence of climate change and atmospheric $\mathrm{N}$ deposition is

24 presented. The methodology is based on 14 indicators for six ecosystem

25 functions: habitat function, net primary function, carbon sequestration, nutrient

26 and water flux, resilience. It allows assessments of ecosystem integrity changes

27 by comparing current or prospective ecosystem states with ecosystem-type

28 specific reference states as described by quantitative indicators for 61 forest

29 ecosystem types based on data before 1990.

30 Conclusion. The method developed enables site-specific classifications of

31 ecosystem integrity as well as classifications with complete coverage and

32 determinations of temporal trends as shown using examples from the Thuringian

33 Forest and the "Kellerwald-Edersee" National Park (Germany). 
35 Keywords

36

37 Ecosystem classification; ecosystem functions; ecosystem structures; ecological

38 indicators; environmental monitoring; Geo-information System; mapping

401 Background

42 Climate change and atmospheric nitrogen inputs can alter the integrity of 43 ecosystems, i.e. their dominant structures and functions, and thus limit their

44 benefits for humans, the ecosystem services. Therefore, action 5 of the EU 45 Biodiversity Strategy to 2020 foresees that Member States will map and assess 46 the state of ecosystems and their services in their national territory. To this end, 47 an operational guidance to the EU and the Member States on how to assess the 48 condition (or the state) of Europe's ecosystems was developed (Maes et al. 49 2018). Accordingly, ecosystem condition should be measured using indicators 50 and specified for the national level of the EU member states (Maes et al. 2018). 
51 For Germany, Jenssen et al. (2013) and Schröder et al. (2015) laid the

52 foundations for a spatially explicit and nationally applicable concept for the

53 classification of changes in ecosystem integrity. This methodology was further

54 deepened and developed by Schröder et al. (2019). It enables an integrative

55 assessment of changes in ecosystem integrity, taking into account the effects of

56 climate change in combination with atmospheric nitrogen $(\mathrm{N})$ deposition.

57 Characteristics of ecosystem integrity concerned are self-organisational capacity,

58 functionality and compliance of abiotic and biotic properties with the natural site

59 potential (identity). The methodology is based on an extensive vegetation

60 database, nationwide available data from digital maps and long-term monitoring

61 programmes. It is complemented by dynamic modelling of future climate and soil

62 conditions. The ecosystem condition is assessed on the basis of the criteria of

63 functionality, chemical and biological characteristics, and stress tolerance to

64 anthropogenic nitrogen inputs and climate change. The methodology allows the

65 identification and mapping of potential natural ecosystem types and current near-

66 natural ecosystem types. For certain climate scenarios and atmospheric nitrogen

67 inputs (2011-2070), possible ecosystem developments can be projected and 
68 evaluated in the future. The concept complements existing assessment methods

69 for ecosystem conditions by taking abiotic environmental factors and their

70 changes into account as drivers of biological changes and ecosystem functions.

71 At the same time it should serve to identify the causes of disturbances as early

72 as possible and to derive suitable measures for the preservation and

73 development of certain ecosystem conditions.

74

75 For the development of the methodology presented in this paper, the Federal

76 Environment Agency has attached importance to use data from monitoring

77 programmes and to cover three spatial levels: the forest stand level as well as

78 the regional and national level. Thereby, the German-wide map of hemeroby

79 (Steinhardt et al. 1999) could not be used since it does not address ecological

80 functions and "is inappropriate for a more accurate calculation of spatial extent

81 and thus the monitoring of local and regional developments" (Walz and Stein

82 2014:2).

83 
84 A fundamental component of the methodology is a classification of Germany's

85 semi-natural ecosystems. Their concordance with other ecosystem

86 classifications for which no spatial concretisation has been carried out nationwide

87 (European Nature Information System EUNIS, Riecken et al. 2006; habitat types

88 according to Annex I of the Habitats Directive) has been achieved. Thus, the

89 developed ecosystem classification is connectable with other approaches and

90 enables ecologically founded interpretation and spatial differentiation. For 61

91 selected ecosystem types, a historical reference condition was quantified based

92 on data from the period 1961-1990 (Jenssen et al. 2013; Schröder et al. 2015).

93 The reference condition was defined as a type-specific condition of ecosystems,

94 the characteristics of which are characterized by intervals of historical ecosystem

95 condition variables (1961-1990). These conditions are relatively least affected by

96 substance inputs and climate change, which can be adequately quantified with

97 measurement data.

99 For selected ecosystem functions (habitat function, net primary function, carbon

100 storage, nutrient flow, water flow and adaptability), indicators were selected with 
101 which current and modelled future ecosystem conditions can be compared with 102 the respective ecosystem type-specific reference conditions. The indication was 103 quantitative with data from monitoring programmes and from the Waldkunde 104 Institut Eberswalde (W.I.E.) database, whereby the focus was on the effects of 105 changes in the abiotic systemic bases of development.

107 The reference states quantified for 40 forest and 21 forest ecosystem types refer 108 to the period up to 1990 , mainly from 1960 onwards, but in individual cases to 109 data dating back to the 1920s and 1930s. For each ecosystem type its reference 110 status is indicated by a data sheet with the following information: water balance type, 3 rd digit = substance cycle type (for description see Schröder et al. 2019, vol.3),

2. Name of ecosystem type,

3. EUNIS class,

4. Biotope type BfN (Riecken et al. 2006),

5. Vegetation type according to common plant sociological classifications, 
6. Photo,

7. Habitat type according to the Fauna-Flora-Habitat Directive (Ssymank et
al. 1998),

8. Position in the two-dimensional ecogram with the coordinates soil moisture and base saturation,

9. Location factors: Soil shape, soil type, terrain, macroclimate,

10. Habitat function: Characteristic species association with continuity and mean quantity development of the soil cover, maximum Kullback distance of the individual records to the mean species quantity distribution, minimum similarity of the individual records with the mean species quantity distribution,

11. Net primary production (NPP): above-ground average annual NPP at the time of culmination in tree wood, leaf/needle mass, ground vegetation and total mass, upper stand height at age 100 as comparative parameter,

12. Carbon storage: Carbon stock in humus ( $\mathrm{C}_{\text {org }}$ in humus layer and in soil up to $80 \mathrm{~cm}$ depth), 
13. Nutrient flow: $\mathrm{pH}$ in $1 / 10 \mathrm{KCl}$, base saturation $\mathrm{V}$ in $\%$ and $\mathrm{C} / \mathrm{N}$ ratio in the uppermost $5 \mathrm{~cm}$ from $\mathrm{H}$ to Ah horizon (interval of mean value and standard deviation), humus form, nutritional characteristics $\mathrm{N} \%, \mathrm{P} \%, \mathrm{~K} \%$, $\mathrm{Ca} \%, \mathrm{Mg} \%$ in the assimilation apparatus of trees in $\mathrm{g} / 100 \mathrm{~g}$ of leaf $/$ needle dry matter (August, interval of mean value and standard deviation),

14. Water flow: Soil moisture index (interval from mean value and standard deviation) as well as

15. Adaptation to changing environmental conditions: maximum proportions of natural site tree species in self-organised development stages.

145 The objective of this contribution is to present the methodology of quantifying the 146 ecosystem functions referred to in paragraphs 10 to 15 and to show how 147 ecosystem integrity is classified on this basis. 
151 The data used and the results produced as well as software tools developed

152 were published as data and software papers (Jenssen et al. 2019 a, 2019 b;

153 Nickel and Schröder 2017 b, 2018).

154

$155 \quad 2.1$ Determination of indicator characteristics

156

$157 \quad 2.1 .1$ Indicators of habitat function

158

159 The habitat function is simply indicated by the composition of the vegetation

160 according to quality (higher plant species as well as species of soil-dwelling

161 mosses and lichens) and quantity (coverage percentage). For this purpose, the

162 Kullback distance (Jenssen et al. 2013; Kullback 1951; Schröder et al. 2015) of

163 the vegetation composition of the study area is calculated from the distribution of

164 the mean species quantities of the reference state (Figure 1).

165

166 Figure 1. Basic scheme for determining the indicators of the habitat function of a

167 current ecosystem type 
16.12.2020 10:45:45

168

169 For each of the individual vegetation relevés representing the reference state, the

170 Kullback distance to the mean species quantity distribution was calculated and

171 from the sum of the mean value and standard deviation of the totality of these

172 distances, a value was calculated characterising the reference state, referred to

173 as the maximum Kullback distance of the individual relevés to the mean species

174 quantity distribution, and documented in the data sheets (Jenssen et al. 2019a)

175 for each ecosystem type. A comparison of the Kullback distance of the

176 vegetation composition of the investigated area with this "limit value" allows a

177 statement on the extent to which the vegetation composition corresponds to the

178 reference condition or not.

179

180 In addition to the Kullback distance, an index is calculated which shows the

181 correspondence of the current quantity development of the vegetation with the

182 mean quantity development of the type (Jenssen 2010):

$183 S\left(p_{1}, . ., p_{S}, p_{1}^{o}, . ., p_{S}^{o}\right)=\sum_{i=1}^{S} \min \left(p_{i}, p_{i}^{o}\right) \cdot 100 \%$ 
184 This similarity index $\mathrm{S}$ is calculated analogously to the Kullback distance 185 (Schröder et al. 2019, Vol. 2: Section 2.3). It allows a comparison to be made 186 with the "limit value", also identified in the data sheets (Jenssen et al. 2019a) as 187 the minimum similarity of the individual relevés representing the reference state 188 with the mean species quantity distribution, which was calculated as the 189 difference between the arithmetic mean of all similarity indices of the individual 190 relevés representing the reference state and their standard deviation.

192 Due to its formal structure as entropy, the Kullback distance emphasizes

193 differences in characteristic combinations of several species, each with medium

194 quantity development, while the similarity index is influenced mainly by

195 agreement of the highly continuous dominating species. This difference may be

196 relevant to the interpretation of habitat function for different groups of plant and

197 animal species in different ecological domains, and therefore both indicators are 198 listed. 
200 Example: ICP1 Forests Level II Location 1605 (Großer Eisenberg, Germany) 201

202 Nickel et al. (2019 b: Table 3) already presented the calculation of the Kullback 203 distance $K D(1960)=0.31$ between the vegetation condition of the investigated 204 area in 1960 and the reference condition of ecosystem type C4-6d-B1. A similar 205 calculation was performed for the vegetation surveys from 2001 and 2006 taken 206 from the Level II database with the results $K D(2001)=1.97$ and $K D 2006)=1.72$. 207 If the KD-values for all images of the reference condition from the years up to 2081990 from Jenssen et al. (2019 a) "C4-6d-B1_Vegetationsgesamttabelle.xls") are 209 calculated in an analogous manner, the sum of the mean value and standard 210 deviation of these KD-values is obtained as the value for the maximum Kullback 211 distance of the individual relevés to the mean species-quantity distribution $\mathrm{KD}_{\max }$ $212=0.53$, which is also shown in Jenssen et al. (2019 a). An analogous calculation 213 of the percentage similarity index $S$ yields values of $S(1960)=69.4 \%, S(2001)=$ $21450.1 \%$ and $S(2006)=60.6 \%$ compared to a minimal similarity of the individual 215 relevés representing the reference state with the mean species quantity

\footnotetext{
1 International Co-operative Programme on Assessment and Monitoring of Air Pollution Effects on Forests.
} 
216 distribution of $S_{\min }=65 \%$. Thus, both calculated indicators for the habitat

217 function show that the typical species composition of the investigated area is

218 clearly disturbed after 2000 , with a reversible development being observed

219 between 2001 and 2006.

220

$221 \quad 2.1 .2$ Indicator Net primary production

222

223 The indicator net primary production refers to the net primary production (NPP) of

224 above-ground wood biomass relevant from a forestry point of view, which is

225 recorded in the form of growth. In order to make it possible to compare this size,

226 which fluctuates greatly with the age and treatment of the stand, with the

227 reference state valid for the respective ecosystem type, the average net primary

228 production of wood biomass at the time of its culmination is calculated from the

229 wood measurement monitoring data using the method outlined in Figure 2 and

230 described below.

231

232 Figure 2. Basic scheme for determining the mean net primary production (NPP) 

mean trunk from the individual tree data recorded on the study area for

1. Calculation of the mean stand height $H G$ as the height of the circular breast height diameter $d_{i}$ and height hi according to the formula

$$
H G=\frac{\sum_{i} d_{i}^{2} \cdot h_{i}}{\sum_{i} d_{i}^{2}}
$$

2. Calculation of the relative height class from the stand age and HG according to the routine BON_REL (Jenssen et al. 2019 b).

3. Calculation of the growth trend depending on the age of the portfolio according to the routine "Growth" (Jenssen et al. 2019 b) and determination of the average total growth DGZ depending on the age of the portfolio. The "Growth" routine in turn accesses the "Stock" routine and, if necessary, the "Diameter" routine (Jenssen et al. 2019 b).

4. Determination of the culmination point of the average timber growth (DGZ). Multiplication of the $D G Z_{\max }$ with the density of the wood species leads to the indicator maximum of the average net primary production $D N P_{\text {max. }}$ 
16.12.2020 10:45:45

250 Example: ICP Forests Level II Location 1605 (Großer Eisenberg, Germany)

252 The calculation of the indicator for the year 1995 is given here as an example:

253 The Level II data set for the area shows individual timber data for 141 trees of the 254 spruce species for 1995.

255 1. The chest height diameter $d_{1,3}$ and the tree height $h$ are given for all 141 trees. In a spreadsheet, the squares of the breast height diameter $\mathrm{d}_{\mathrm{i}}^{2}(\mathrm{I}=$ $1 . . .141$, i indicates the line number) in column 1 and the individual tree heights $h_{i}$ in column 2 are imported. In column 3 the multiplication $d_{i}^{2} h_{i}$ is executed. The sum over column 3 is divided by the sum over column 1 and one receives in the result the inventory mean height to $\mathrm{HG}=18.6 \mathrm{~m}$.

2. According to the Level II data set, the respective forest stand was allocated to age group 5 (80 - 100 years) in 1995. An average population age of 90 years is derived from this. The routine BON_REL (ET; ALT; HOE_MITT) (Jenssen et al. 2019b) is used to determine the relative altitude creditworthiness. The spruce yield table marked with the variable 
$E T=4$ is used, the stock age is entered with $A L T=90$ and the mean height with HOE_MITT $=18.6$ according to point 1 . The result is the relative height credit rating $B O N \_R E L(4 ; 90 ; 18.6)=4.46$.

3. With the help of the routine ZUWACHS (ET; ALT; BON_REL), with ET = 4 and BON_REL $=4.46$ for a sufficient interval of the stand age, the growth course of an optimally stocked spruce stand is now calculated using the location quality calculated for the stand as a function of the stand age $A L T$. For each calculated age of $A L T$, the average annual total growth DGZ of the previous stock development is obtained by dividing the sum of the annual increases (= total growth) by the reached age of ALT. The result is the course of the DGZ depending on the age of the stand for an optimally stocked spruce stand according to the forestry management model specified by the yield table.

4. The maximum of the DGZ curve calculated according to point 3 corresponds to the average annual total growth at the time of culmination, $\mathrm{DGZ}_{\max }=13.03 \mathrm{~m} 3 / \mathrm{ha}$, or after multiplication by the density 282 of $0.378 \mathrm{tDM} / \mathrm{m} 3$ the average annual net primary production of tree 
wood $\mathrm{DNP}_{\max }=4.93 \mathrm{t} / \mathrm{ha}$ under the assumption that the stand would have the stocking density assumed in the yield table model.

5. However, for the calculation of the growth trend, the typical stocking density identified for the reference ecosystem type shall be taken into account. The data sheet on the reference condition of the RohhumusFichten-Hochbergwald (C4-6d-B1; Raw-humus spruce forest on the altimontane level) (Jenssen et al. 2019 a) shows an average stand height of $22 \mathrm{~m}$ at the age of 100 years. This results in a relative height class rating of BON_REL $(4 ; 100 ; 22)=3.97$ for the mean reference condition. Using the GROWTH $(4 ; \mathrm{ALT} ; 3,97)$ routine, the average annual net primary production of tree wood $\mathrm{DNP}_{\max }=5,58 \mathrm{t} / \mathrm{ha}$ is now calculated using the method described in point 3 , assuming that the reference condition would have the stocking density assumed in the yield table model. In fact, however, it is a natural spruce forest in the ecological battle zone between a closed high forest and an open grove vegetation with a stocking density significantly reduced compared to the 299 forest yield table model, which in turn leads to a proportional reduction of 
stock and hectare -related growth. The data sheet on the reference condition of the Rohhumus-Fichten-Hochbergwald (C4-6d-B1; Rawhumus spruce forest on the altimontane level) (Jenssen et al. 2019 a) shows an average annual net primary production of $\mathrm{DNP}_{\max }=2.2 \mathrm{t} / \mathrm{ha}$. This results in a reduction factor of $2.2 / 5.58=0.394$, by which the average annual net primary production of tree wood $\mathrm{DNP}_{\max }=4.93 \mathrm{t} / \mathrm{ha}$ determined under point 4 must be multiplied, so that an average annual net primary production of tree wood $\mathrm{DNP}_{\max }=1.94 \mathrm{t} / \mathrm{ha}$ is obtained as an indicator of the net primary production of the tree stock of the monitoring area "Großer Eisenberg".

311 As an indicator for carbon storage, the carbon stored in the humus of the organic 312 layer and in the mineral soil between 0 and $80 \mathrm{~cm}$ deep is calculated (Figure 3).

\subsubsection{Indicator Carbon storage}

315

316 Figure 3. Basic scheme for determining the $\mathrm{C}_{\text {org }}$ content in humus 
318 The quantities of $\mathrm{C}_{\text {org }}$ in $\mathrm{g} / \mathrm{kg}$ given for the individual soil horizons are multiplied 319 by the respective bulk density $(\mathrm{kg} / \mathrm{m} 3)$ and converted into stock values per 320 hectare using the respective horizon thickness data.

322 If the data for individual horizons do not contain information on bulk density, the 323 volume-related $\mathrm{C}$ reserves can alternatively be calculated on the basis of an 324 empirical relationship between $\mathrm{C}$ content and litre weight of the fine soil 325 according to Hofmann (1974:54). After conversion, the following formula results 326 from this relationship for calculating the bulk density $[\mathrm{kg} / \mathrm{m} 3]$ as a function of the 327 organic carbon content $[\mathrm{g} / \mathrm{kg}]$ : Bulk density $=1593 /$ Corgo $0^{177465}$.

329 Example: ICP Forests Level II site 1605 (Großer Eisenberg, Thuringian Forest, 330 Germany)

332 The sample calculation was performed using the Level II data for 2009 (Table 1).

333 The mean value for $C_{\text {org }}[\mathrm{g} / \mathrm{kg}]$ was calculated for each of several measurements 
334 given per layer. For the layers of the mineral soil M01 $(0-10 \mathrm{~cm}), \mathrm{M} 12(10-20$

$335 \mathrm{~cm})$, M24 $(20-40 \mathrm{~cm})$ and M48 $(40-80 \mathrm{~cm})$ the bulk density was calculated

336 according to the empirical formula given above. The hectare stocks of organic

337 carbon obtained by multiplying $\mathrm{C}_{\text {org }}[\mathrm{g} / \mathrm{kg}]$ by bulk density $[\mathrm{kg} / \mathrm{m} 3]$ were summed

338 across all layers.

339

340 Table 1. Calculation of the content of organic carbon in the litter layer and in the soil block up to $80 \mathrm{~cm}$ depth from the Level II data for the year 2009

\begin{tabular}{l|r|r|r|r|r}
\hline Shift & $\begin{array}{c}\text { Layer } \\
\text { thickness } \\
\text { [cm] }\end{array}$ & $\begin{array}{c}\text { Number of } \\
\text { measurements } \\
\text { in each layer }\end{array}$ & $\begin{array}{c}\text { Corg } \\
\text { [g/kg] }\end{array}$ & $\begin{array}{c}\text { Bulk } \\
\text { density } \\
{[\mathbf{k g} / \mathbf{m} 3]}\end{array}$ & $\begin{array}{c}\mathbf{C}_{\text {org }} \\
{[\mathbf{t} / \mathbf{h a}]}\end{array}$ \\
\hline Of+Oh & 6 & 8 & 362,8 & 62 & 13,4 \\
\hline M01 & 10 & 8 & 28,7 & 878 & 25,2 \\
\hline M12 & 10 & 8 & 12,3 & 1021 & 12,5 \\
\hline M24 & 20 & 8 & 8,5 & 1089 & 18,6 \\
\hline M48 & 40 & 9 & 3,1 & 1306 & 16,0 \\
\hline Total & $\begin{array}{r}\text { Top layer } \\
+\mathbf{8 0} \mathbf{~ c m} \\
\text { mineral soil }\end{array}$ & & & & $\mathbf{8 5 , 7 0}$ \\
\hline
\end{tabular}


345 Nutrient and water flow indicators are calculated using indicator value models

346 (Figure 4).

347

348 Figure 4. Basic scheme for the determination of indicators of water and nutrient

349 flow

350

$351 \quad$ 2.1.4.1 Indicator value model for calculating the $\mathrm{C} / \mathrm{N}$ and $\mathrm{pH}$ of the topsoil 352

353 The indicator value model calculates for a given vegetation survey a probability

354 distribution over the $\mathrm{C} / \mathrm{N}$ ratio and the $\mathrm{pH}(\mathrm{KCl})$ of the topsoil (top $5 \mathrm{~cm}$ of the

355 humus layer or mineral soil). The $\mathrm{C} / \mathrm{N}$ ratio serves as an indicator of nutrient

356 availability similar to the N number according to Ellenberg et al. (1992). From this

357 distribution, an expected value for the $\mathrm{C} / \mathrm{N}$ ratio and the $\mathrm{pH}$ of the topsoil is

358 calculated. A complete documentation of the model is contained in Jenssen et al.

359 (2019 b).

360 
361 The basis for the modelling of the $\mathrm{C} / \mathrm{N}$ ratio and the $\mathrm{pH}$ are the probability

362 distributions of the most frequent plant species of the Central European forest

363 vegetation, taking into account their stratum affiliation and quantity development

364 (Jenssen et al. 2019 b: Tables 3 and 6, respectively). These distributions are

365 multiplicatively linked to a probability distribution for the ecotope characterised by

366 the vegetation uptake. From the resulting distribution, the characteristic values

367 can be assigned to the ecotope. In the applications performed, the expected

368 value assigned to the ecotope was the arithmetic mean of the class values of the

$369 \mathrm{C} / \mathrm{N}$ ratio or the $\mathrm{pH}$ weighted with the class probabilities of the resulting

370 probability distribution (Jenssen et al. 2019 b: Tables 1 and 4).

371

372 The following model algorithm has been implemented:

373 1. Reading a table (tblVEG) with the vegetation relevé including all

374 occurring species separated by tree layer, lower and upper shrub layer,

375 field layer and the corresponding percentage cover values.

376 2. Reading the class mean values $\mathrm{C} / \mathrm{N}$ and pH (Jenssen et al. 2019b: Table

377 1 and 4) for 20 classes respectively. 
3. Calculation of the probability densities of the occurring species taking into account stratification and cover value class using the function

$$
f(x)=a_{0} \cdot \exp \left[-\frac{\left(x-a_{1}\right)^{2}}{2 \cdot a_{2}^{2}}\right]+a_{3}+a_{4} \cdot x+a_{5} \cdot x^{2}
$$

and the parameters according to Jenssen et al. (2019 b: Tables 3 and 6 , respectively), if these are included in the tables. The parameter "Number" is the number of distributions included in the calculation. The deciduous tree species in brackets in the tables are not taken into account due to possibly dominant forestry influences which may falsify the indicator value.

If there are negative values for $f(x)$, these are set to zero. The probability densities are then normalized to 1 by dividing each $f(x)$ by the sum of all $f(x)$ over all 20 classes.

4. Create a matrix (number, 20) containing the respective probability densities above the class values for the considered plant species (if necessary, separated by strata and cover value class).

5. Multiplicative linking of probability densities 


$$
p d(*)=\prod_{i=1}^{A n z a h l} \operatorname{Matrix}(i, *)
$$

for each of the 20 classes. The resultung vector pd contains the probability density for each of the 20 class values.

6. Weighting of the probability density vector pd with the case numbers of the individual classes (column "Absolute frequency" in Jenssen et al. 2019 b: Tables 1, 4).

7. Calculation of the expected value for the $\mathrm{C} / \mathrm{N}$ ratio or the $\mathrm{pH}$ as an average over the class values of the $\mathrm{C} / \mathrm{N}$ ratio or the $\mathrm{pH}$ weighted with the probability densities $\mathrm{pd}$.

404 Example: ICP Forests Level II site 1605 (Großer Eisenberg, Germany)

405

406 The calculation should be performed using an executable program that

407 implements the algorithm described above based on the data documented by

408 Jenssen et al. (2019 b). For a better comprehensibility of the model algorithm, a 409 spreadsheet calculation was carried out in Table 2 for the vegetation survey of 410 the ICP Forests site LII-1605 from 1960, which is documented under the area 
411 designation STO 180 in Jenssen et al. (2019a) ("C4-6d-

412 B1_Vegetationsgesamttabelle.xls").

414 The first two columns contain the plant species taken from the vegetation survey

415 separately by stratum and the corresponding percentage cover values (step 1 of

416 the model algorithm). The first row contains the class mean values $\mathrm{C} / \mathrm{N}$ (Jenssen

417 et al. 2019 b: Table 1) for 20 classes each (step 2). The inner fields of the table

418 contain the probability densities calculated according to steps 2 and 3 for the

419 occurring species over the respective classes, provided that a density function

420 (parameters in Jenssen et al. 2019 b) exists for the species. The probability

421 densities were normalized so that their sum over all classes of the $\mathrm{C} / \mathrm{N}$ ratio (row

422 sum, stored in the last column) results in one. In the row "Column product" the

423 probability densities of the different plant species were multiplied by the

424 respective $\mathrm{C} / \mathrm{N}$ classes (step 4). In the next row "Column product, weighed with

425 class frequencies" the probability densities are weighed with the case numbers

426 (absolute frequencies) of the individual classes from Jenssen et al. (2019b: Table

427 1) (step 5). This is to ensure that the two extreme classes with a significantly 
428 lower number of underlying measured values and correspondingly lower 429 statistical representation are given a lower weighting in the calculation of the 430 expected value (explanations in Jenssen et al. 2019 b). In our example, however, 431 these classes have a zero probability, so step 5 has no effect on the result 432 (Table 2). The modal value of the distribution remains unchanged above the 433 class with the class value $\mathrm{C} / \mathrm{N}=28$.2. The corresponding class probability is 43 $434 \%$ after normalization across all classes. In the last line, the expected value for 435 the topsoil $\mathrm{C} / \mathrm{N}$ ratio of the investigated area is calculated by multiplying the class 436 values with the respective class probabilities and then summing all classes (step 437 6). The result for the expected value is $\mathrm{C} / \mathrm{N}=27.4$. A completely analogous 438 calculation is carried out to determine the $\mathrm{pH}(\mathrm{KCl})$ in the topsoil. $\mathrm{pH}=2.8$ is 439 obtained. 
Table 2. Calculation of the expected value of the $\mathrm{C} / \mathrm{N}$ ratio in the topsoil of the ICP Forests site LII-1605 site (Großer Eisenberg, Thuringian Forest, Germany) in 1960 from the probability densities (pdf) of the occurring plant species for 20 classes of the $\mathrm{C} / \mathrm{N}$ ratio

\begin{tabular}{|c|c|c|c|c|c|c|c|c|c|c|c|c|c|c|c|c|c|c|c|c|c|c|}
\hline Species & $\begin{array}{c}\text { C/N } \\
\text { Cov } \%\end{array}$ & 9.7 & 11.4 & 12.5 & 13.2 & 13.8 & 14.5 & 15.5 & 16.6 & 17.9 & 19.4 & 20.9 & 22.5 & 23.8 & 25.2 & 26.7 & 28.2 & 29.7 & 31.7 & 34.1 & 38.4 & $\begin{array}{l}\text { Sum } \\
\text { Line }\end{array}$ \\
\hline \multicolumn{23}{|l|}{$\begin{array}{l}\text { Upper tree } \\
\text { layer }\end{array}$} \\
\hline Picea abies & 15 & & & & & & & & & & & & 1 & & & & & & & & & \\
\hline \multicolumn{23}{|l|}{$\begin{array}{l}\text { Lower tree } \\
\text { layer }\end{array}$} \\
\hline Picea abies & 60 & & & & & & & & & & & & & & & & & & & & & \\
\hline \multicolumn{23}{|l|}{ shrub layer } \\
\hline Picea abies & 87 & & & & & & & & & & & & & & & & & & & & & \\
\hline $\begin{array}{l}\text { Sorbus } \\
\text { aucuparia }\end{array}$ & $r$ & 0.015 & 0.022 & 0.027 & 0.031 & 0.034 & 0.039 & 0.045 & 0.052 & 0.061 & 0.069 & 0.076 & 0.080 & 0.081 & 0.079 & 0.075 & 0.067 & 0.059 & 0.046 & 0.031 & 0.012 & 1.0 \\
\hline $\begin{array}{l}\text { sylvatica } \\
\text { fagus }\end{array}$ & + & 0.026 & 0.050 & 0.060 & 0.065 & 0.068 & 0.071 & 0.073 & 0.073 & 0.071 & 0.068 & 0.064 & 0.058 & 0.054 & 0.048 & 0.043 & 0.037 & 0.032 & 0.024 & 0.015 & 0.000 & 1.0 \\
\hline \multicolumn{23}{|l|}{ Herb layer } \\
\hline $\begin{array}{l}\text { Calamagrostis } \\
\text { villosa }\end{array}$ & 15 & 0.000 & 0.000 & 0.001 & 0.006 & 0.009 & 0.013 & 0.018 & 0.023 & 0.029 & 0.034 & 0.038 & 0.041 & 0.043 & 0.049 & 0.111 & 0.257 & 0.235 & 0.059 & 0.027 & 0.005 & 1.0 \\
\hline $\begin{array}{l}\text { Vaccinium } \\
\text { myrtillus }\end{array}$ & 37 & 0.000 & 0.000 & 0.000 & 0.000 & 0.000 & 0.000 & 0.001 & 0.006 & 0.013 & 0.024 & 0.037 & 0.053 & 0.068 & 0.086 & 0.107 & 0.131 & 0.157 & 0.191 & 0.068 & 0.060 & 1.0 \\
\hline $\begin{array}{l}\text { Deschampsia } \\
\text { flexuosa }\end{array}$ & 37 & 0.000 & 0.000 & 0.001 & 0.003 & 0.006 & 0.009 & 0.015 & 0.023 & 0.033 & 0.047 & 0.062 & 0.078 & 0.089 & 0.100 & 0.109 & 0.113 & 0.111 & 0.100 & 0.076 & 0.024 & 1.0 \\
\hline $\begin{array}{l}\text { Galium } \\
\text { saxatile }\end{array}$ & 15 & 0.000 & 0.001 & 0.007 & 0.011 & 0.014 & 0.017 & 0.022 & 0.026 & 0.031 & 0.037 & 0.044 & 0.057 & 0.078 & 0.108 & 0.137 & 0.141 & 0.118 & 0.075 & 0.047 & 0.029 & 1.0 \\
\hline
\end{tabular}




\begin{tabular}{|c|c|c|c|c|c|c|c|c|c|c|c|c|c|c|c|c|c|c|c|c|c|c|}
\hline $\begin{array}{l}\text { Trientalis } \\
\text { europaea }\end{array}$ & 15 & 0.000 & 0.000 & 0.000 & 0.000 & 0.000 & 0.001 & 0.002 & 0.004 & 0.008 & 0.018 & 0.037 & 0.066 & 0.095 & 0.127 & 0.153 & 0.162 & 0.150 & 0.111 & 0.057 & 0.008 & 1.0 \\
\hline $\begin{array}{l}\text { Dryopteris } \\
\text { dilatata }\end{array}$ & + & 0.000 & 0.015 & 0.038 & 0.055 & 0.068 & 0.081 & 0.095 & 0.103 & 0.103 & 0.095 & 0.082 & 0.068 & 0.056 & 0.045 & 0.035 & 0.026 & 0.018 & 0.010 & 0.004 & 0.003 & 1.0 \\
\hline $\begin{array}{l}\text { Maianthemum } \\
\text { bifolium }\end{array}$ & + & 0.038 & 0.052 & 0.062 & 0.068 & 0.073 & 0.078 & 0.083 & 0.087 & 0.087 & 0.081 & 0.071 & 0.057 & 0.046 & 0.035 & 0.025 & 0.018 & 0.013 & 0.010 & 0.008 & 0.008 & 1.0 \\
\hline $\begin{array}{l}\text { pteridium } \\
\text { aquilinum }\end{array}$ & + & 0.000 & 0.004 & 0.011 & 0.016 & 0.021 & 0.028 & 0.047 & 0.091 & 0.146 & 0.128 & 0.072 & 0.055 & 0.055 & 0.056 & 0.056 & 0.055 & 0.053 & 0.048 & 0.040 & 0.017 & 1.0 \\
\hline Luzula pilosa & + & 0.006 & 0.015 & 0.027 & 0.036 & 0.044 & 0.054 & 0.066 & \begin{tabular}{|l|}
0.078 \\
\end{tabular} & \begin{tabular}{|l|}
0.087 \\
\end{tabular} & 0.092 & 0.091 & 0.084 & 0.076 & 0.066 & 0.055 & 0.044 & 0.034 & 0.023 & 0.014 & 0.010 & 1.0 \\
\hline \multicolumn{23}{|l|}{ Moss layer } \\
\hline $\begin{array}{l}\text { Dicranum } \\
\text { scoparium }\end{array}$ & + & 0.000 & 0.005 & 0.009 & 0.011 & 0.013 & 0.015 & 0.017 & 0.020 & 0.024 & 0.029 & 0.035 & 0.045 & 0.056 & 0.072 & 0.091 & 0.110 & 0.127 & 0.138 & 0.127 & 0.058 & 1.0 \\
\hline $\begin{array}{l}\text { Barbilophozia } \\
\text { floerkei }\end{array}$ & + & & & & & & & & & & & & & & & & & & & & & \\
\hline $\begin{array}{l}\text { Pleurozium } \\
\text { schreberi }\end{array}$ & 3 & 0.000 & 0.003 & 0.010 & 0.014 & 0.017 & 0.020 & 0.025 & 0.029 & 0.034 & 0.038 & 0.042 & 0.047 & 0.053 & 0.064 & 0.082 & 0.106 & 0.130 & 0.146 & 0.121 & 0.020 & 1.0 \\
\hline $\begin{array}{l}\text { Lophocolea } \\
\text { heterophylla }\end{array}$ & + & & & & & & & & & & & & & & & & & & & & & \\
\hline $\begin{array}{l}\text { Dicranum } \\
\text { majus }\end{array}$ & 15 & & & & & & & & & & & & & & & & & & & & & \\
\hline $\begin{array}{l}\text { Column } \\
\text { product. }\end{array}$ & & $0.0 \mathrm{E}+\mathrm{C}$ & 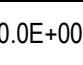 & s. & S & $.0 \mathrm{CT}$ & . & $20-26$ & $.2 \mathrm{E}-20$ & $3 \mathrm{E}-$ & 1.2E-17 & E-17 & 1.1. & $\mathrm{E}$ & E- & 7E- & 8E- & E- & $3 E-1$ & $8 \mathrm{E}-2$ & $.0 \mathrm{E}+0$ & $6.5 \mathrm{E}-15$ \\
\hline $\begin{array}{l}\text {... weighed } \\
\text { with class } \\
\text { frequencies }\end{array}$ & & $E+U$ & & & L & $L T$ & $E+00$ & E- & $\mathrm{E}-21$ & 1E-20 & $4 \mathrm{E}-19$ & $9 \mathrm{E}-1$ & $5.8 \mathrm{E}-18$ & 4E-17 & $E-$ & $1.3 \mathrm{E}-$ & bE & $7.9 \mathrm{E}-$ & $1.2 \mathrm{E}$ & 4E-2 & $0.0 \mathrm{E}+\mathrm{C}$ & $3.5 \mathrm{E}-16$ \\
\hline $\begin{array}{l}\ldots \text { and } \\
\text { standardised } \\
\text { (pdf) }\end{array}$ & & 0.000 & 0.000 & 0.000 & 0.000 & 0.000 & 0.000 & 0.000 & 0.000 & 0.000 & 0.002 & 0.006 & 0.017 & 0.041 & 0.089 & 0.268 & 0.434 & 0.140 & 0.003 & 0.000 & 0.000 & 1.0 \\
\hline $\begin{array}{l}\text { pdf }{ }^{*} \mathrm{C} / \mathrm{N} \\
\text { class value }\end{array}$ & & 0.00 & 0.00 & 0.00 & 0.00 & 0.00 & 0.00 & 0.00 & 0.00 & 0.00 & 0.04 & 0.12 & 0.38 & 0.98 & 2.24 & 7.16 & 12.24 & 4.16 & 0.11 & 0.00 & 0.00 & 27.4 \\
\hline
\end{tabular}




\subsubsection{Indicator value model for calculating the base saturation of the topsoil}

So far, no probability density functions have been created for base saturation (V). Therefore, with the help of 787 measurements of the $\mathrm{V}$-value available in the W.I.E. database and on the basis of a close correlation to the $\mathrm{pH}$-values, a total of 838 forest plant species were assigned mean values of the base saturation of the topsoil (Jenssen et al. 2019 b: Table 9). For the calculation of an area-related base saturation, an average value weighted with the cover values was calculated. This value is subject to corresponding uncertainties compared to the $\mathrm{C} / \mathrm{N}$ ratios and $\mathrm{pHs}$.

Example: ICP Forests Level II site 1605 (Großer Eisenberg, Thuringian Forest, Germany)

Table 3. shows the calculation of the base saturation for the ICP Forests site LII1605 (Großer Eisenberg, Thuringian Forest, Germany) in 1960 on the basis of 
the vegetation survey of the site LII-1605 from 1960, which is documented under the area designation STO 180 in Jenssen et al. (2019 a) ("C4-6dB1_Vegetationsgesamttabelle.xls"). The first two columns contain the plant species taken from the vegetation survey and the corresponding percentage cover values, whereby the values $r=0.01 \%$ and $+=0.1 \%$ were set. The third column contains the mean $\mathrm{V}$ values of the individual plant species taken from Jenssen et al. (2019 b: Table 9). The last column contains the products from these $\mathrm{V}$-values and the coverage percentage, i.e. the products from the two previous columns. In the last row, the column sum of these products is divided by the sum of the cover percentages taken into account and the result 17 is shown as an area-related $\mathrm{V}$-value.

Table 3. Calculation of the base saturation $(V)$ in the topsoil of the ICP Forests LII-1605 site (Großer Eisenberg, Thuringian Forest, Germany) in 1960 as weighted mean of $\mathrm{V}$ indicated by occurring plant species

\begin{tabular}{l|c|l|l}
\hline Species & Cov\% & V-value & V-value * Cov\% \\
\hline Upper tree layer & & & \\
\hline Picea abies & 15.00 & & \\
\hline Lower tree layer & & & \\
\hline
\end{tabular}




\begin{tabular}{l|c|c|c}
\hline Picea abies & 60.00 & & \\
\hline Shrub layer & & & \\
\hline Picea abies & 87.00 & 19.4 & 1691.9 \\
\hline Sorbus aucuparia & 0.01 & 29.1 & 0.29 \\
\hline sylvatica fagus & 0.10 & 36.3 & 3.63 \\
\hline Herb layer & & & \\
\hline Calamagrostis villosa & 15.00 & 6.2 & 92.75 \\
\hline Vaccinium myrtillus & 37.00 & 19.7 & 727.68 \\
\hline Deschampsia flexuosa & 37.00 & 22.1 & 817.26 \\
\hline Galium saxatile & 15.00 & 12.8 & 191.51 \\
\hline Trientalis europaea & 15.00 & 10.4 & 156.71 \\
\hline Dryopteris dilatata & 0.10 & 27.7 & 2.77 \\
\hline Maianthemum bifolium & 0.10 & 36.0 & 3.60 \\
\hline pteridium aquilinum & 0.10 & 27.9 & 2.79 \\
\hline Luzula pilosa & 0.10 & 31.6 & 3.16 \\
\hline Moss layer & & & \\
\hline Dicranum scoparium & 0.10 & 21.8 & 2.18 \\
\hline Barbilophozia floerkei & 0.10 & 4.3 & \\
\hline Pleurozium schreberi & 3.00 & 22.5 & 67.41 \\
\hline Lophocolea heterophylla & 0.10 & 32.3 & 3.23 \\
\hline Dicranum majus & 15.00 & 4.0 & \\
\hline sum & 224.81 & & 3766.83 \\
\hline V-value, weighed with Cov\%. & & 17 & \\
\hline
\end{tabular}

\subsubsection{Indicator value model for calculating the moisture index of the topsoil}

The modelling of the moisture indicators for the topsoil is based on the scaled

DKF soil moisture index estimates of the topsoil moisture derived by Hofmann 
(2002, pp. 204-214) for sociological-ecological species groups (Jenssen et al. 2019 b: Tables 7 and 8 respectively). From the given soil moisture intervals a Gaussian function is calculated, which approximates a normal distribution of the soil moisture indices in the given interval. The calculation of a moisture index characterizing the test area is carried out analogously to the calculation of the $\mathrm{C} / \mathrm{N}$ and $\mathrm{pH}$ expected values. The probability densities for the respective plant species are weighted with the cover values from the vegetation survey.

The following model algorithm has been implemented:

1. Reading a table (tblVEG) with the vegetation picture contains all occurring species.

2. Definition of 20 classes distributed equidistantly between the extremes 0 and 10 and reading the class averages.

3. Approximation of the probability densities of the occurring species with the function

$$
f(x)=\frac{1}{\sqrt{2 \pi} \cdot \sigma} \cdot \exp \left[-\frac{(x-m)^{2}}{2 \cdot \sigma^{2}}\right]
$$

and the parameters 


$$
m=D K F_{\text {min }}+\sigma \quad, \quad \sigma=\frac{D K F_{\text {max }}-D K F_{\text {min }}}{2}
$$

according to Jenssen et al. (2019b: Table 8), if these are included in the tables. The probability densities are then normalized to one by dividing each $f(x)$ by the sum of all $f(x)$ over all 20 classes.

4. Create a matrix (number, 20) containing the approximated probability densities above the class values for the plant species considered. The parameter "Number" is the number of distributions included in the calculation.

5. Weighting of the approximated probability densities over the class values with the cover values of the species summed across all strata.

6. Multiplicative linking of probability densities

$$
p d(*)=\prod_{i=1}^{A n z a h l} \operatorname{Matrix}(i, *)
$$

for each of the 20 classes. You get a vector pd that contains the resulting probability density for each of the 20 class values. Normalization of the resulting probability density across all classes to one. 
7. Calculation of a surface-related topsoil moisture as mean value over the class values of the topsoil moisture weighed with the probability densities pd.

Example: ICP Forests Level II Location 1605 (Großer Eisenberg, Thuringian Forest, Germany)

Table 4 comprehends the characteristic values for the parameterization of the moisture distribution functions of the plant species occurring in 1960 on the at ICP Forests site LII-1605 (Großer Eisenberg, Thuringian Forest, Germany), which are documented under the area designation STO 180 in Jenssen et al (2019b; "C4-6d-B1_Vegetationsgesamttabelle.xls"). The characteristic values DKFmin and DKFmax, which designate the lower and upper limits of the moisture index of the topsoil scaling between the extremes 0 and 10, are taken from Jenssen et al. (2019 b: Table 8). From this, the parameters of a normal distribution according to step 3 were derived. 
The first row of Table 5 contains the class mean values of 20 equidistantly distributed classes of topsoil moisture between the extremes 0 and 10 (step 2). The inner cells contain the class probabilities (probability densities) calculated for each type of shrub layer and ground vegetation occurring and for each class mean according to the formula given in step 3 (probability densities) normalized to one across all classes (last column, step 4). Table 6 shows the class probabilities multiplied by the respective percentage cover values (second column) (probability densities, step 5). The row "Column product" contains the product of the class probability pages calculated for each moisture class and weighted with the cover values of the species. In the line below, the class probabilities (probability densities) were normalized to one across all classes. The greatest probability of $45 \%$ is calculated for the class between the moisture index 5.5 (medium to permanently fresh) and 6 (permanently fresh). These values were multiplied in the lowest line by the respective class values of the moisture index. The sum of the lines is the expected value of the moisture content of the topsoil on the test area and gives the ratio 5.6 (step 7). 
Table 4. Parameters of the soil moisture distribution functions of the plant species at site LII-1605 (Großer Eisenberg, Thuringian Forest, Germany) in 1960

\begin{tabular}{l|c|c|c|c|c}
\hline $\begin{array}{l}\text { Species } \\
\begin{array}{l}\text { Upper tree } \\
\text { layer }\end{array}\end{array}$ & Cov\% & DKFmin & DKFmax & $\mathrm{m}$ & sigma \\
\hline $\begin{array}{l}\text { Picea abies } \\
\text { Lower tree } \\
\text { layer }\end{array}$ & 15 & & & & \\
\hline Picea abies & 60 & & & & \\
\hline $\begin{array}{l}\text { Shrub layer } \\
\text { Picea abies }\end{array}$ & 87 & 4.0 & 9.0 & 6.50 & 2.50 \\
\hline $\begin{array}{l}\text { Sorbus } \\
\text { aucuparia }\end{array}$ & $\mathrm{r}$ & 3.0 & 6.0 & 4.50 & 1.50 \\
\hline $\begin{array}{l}\text { sylvatica fagus } \\
\text { Herb layer }\end{array}$ & + & 2.0 & 6.5 & 4.25 & 2.25 \\
\hline $\begin{array}{l}\text { Calamagrostis } \\
\text { villosa }\end{array}$ & 15 & 4.0 & 8.0 & 6.00 & 2.00 \\
\hline $\begin{array}{l}\text { Vaccinium } \\
\text { myrtillus }\end{array}$ & 37 & 3.5 & 8.0 & 5.75 & 2.25 \\
\hline $\begin{array}{l}\text { Deschampsia } \\
\text { flexuosa }\end{array}$ & 37 & 2.5 & 7.0 & 4.75 & 2.25 \\
\hline $\begin{array}{l}\text { Galium } \\
\text { saxatile }\end{array}$ & 15 & 2.5 & 7.0 & 4.75 & 2.25 \\
\hline $\begin{array}{l}\text { Trientalis } \\
\text { europaea }\end{array}$ & 15 & 3.0 & 7.0 & 5.00 & 2.00 \\
\hline $\begin{array}{l}\text { Dryopteris } \\
\text { dilatata }\end{array}$ & + & 5.0 & 8.0 & 6.50 & 1.50 \\
\hline $\begin{array}{l}\text { Maianthemum } \\
\text { bifolium }\end{array}$ & + & 3.0 & 7.0 & 5.00 & 2.00 \\
\hline $\begin{array}{l}\text { pteridium } \\
\text { aquilinum }\end{array}$ & + & 5.5 & 8.0 & 6.75 & 1.25 \\
\hline \begin{tabular}{l} 
Luzula pilosa \\
\hline
\end{tabular} & + & 3.0 & 7.0 & 5.00 & 2.00 \\
\hline
\end{tabular}




\begin{tabular}{l|c|c|c|c|c}
\hline Moss layer & & & & & \\
\hline $\begin{array}{l}\text { Dicranum } \\
\text { scoparium }\end{array}$ & + & 2.0 & 6.0 & 4.00 & 2.00 \\
\hline $\begin{array}{l}\text { Barbilophozia } \\
\text { floerkei }\end{array}$ & + & 3.0 & 7.5 & 4.75 & 2.75 \\
\hline $\begin{array}{l}\text { Pleurozium } \\
\text { schreberi }\end{array}$ & 3 & 5.0 & 7.0 & 6.00 & 1.00 \\
\hline $\begin{array}{l}\text { Lophocolea } \\
\text { heterophylla }\end{array}$ & + & 5.0 & 7.5 & 6.25 & 1.25 \\
\hline $\begin{array}{l}\text { Dicranum } \\
\text { majus }\end{array}$ & 15 & 2.00 \\
\hline Explanaion:
\end{tabular}

Explanation: DKFmin and DKFmax denote the lower and upper limits respectively of a moisture characteristic of the topsoil scaling between the extremes 0 and $10, m$ and sigma denote the characteristic values of a normal distribution approximated therefrom. 
Table 5. Calculation of the class probabilities (probability densities) of the plant species at the ICP Forests LII-1605

site (Großer Eisenberg, Thuringian Forest, Germany) in 1960 for 20 classes of the soil moisture index scaled

\section{between the extremes 0 and 10}

\begin{tabular}{|c|c|c|c|c|c|c|c|c|c|c|c|c|c|c|c|c|c|c|c|c|c|c|}
\hline Species & $\begin{array}{c}\text { DKF } \\
\text { Cov\% }\end{array}$ & 0.25 & 0.75 & 1.25 & 1.75 & 2.25 & 2.75 & 3.25 & 3.75 & 4.25 & 4.75 & 5.25 & 5.75 & 6.25 & 6.75 & 7.25 & 7.75 & 8.25 & 8.75 & 9.25 & 9.75 & $\begin{array}{l}\text { Sum } \\
\text { Line }\end{array}$ \\
\hline \multicolumn{23}{|l|}{$\begin{array}{l}\text { Upper tree } \\
\text { layer }\end{array}$} \\
\hline Picea abies & 15 & & & & & & & & & & & & & & & & & & & & & \\
\hline \multicolumn{23}{|l|}{$\begin{array}{l}\text { Lower tree } \\
\text { layer }\end{array}$} \\
\hline Picea abies & 60 & & & & & & & & & & & & & & & & & & & & & \\
\hline \multicolumn{23}{|l|}{ Shrub layer } \\
\hline Picea abies & 87 & 0.004 & 0.006 & 0.010 & 0.014 & 0.021 & 0.028 & 0.037 & 0.048 & 0.058 & 0.068 & 0.077 & 0.083 & 0.087 & 0.087 & 0.083 & 0.077 & 0.068 & 0.058 & 0.048 & 0.037 & 1.000 \\
\hline $\begin{array}{l}\text { Sorbus } \\
\text { aucuparia }\end{array}$ & 0.01 & 0.002 & 0.006 & 0.013 & 0.025 & 0.043 & 0.067 & 0.094 & 0.118 & 0.131 & 0.131 & 0.118 & 0.094 & 0.067 & 0.043 & 0.025 & 0.013 & 0.006 & 0.002 & 0.001 & 0.000 & 1.000 \\
\hline $\begin{array}{l}\text { sylvatica } \\
\text { fagus }\end{array}$ & 0.1 & 0.019 & 0.027 & 0.038 & 0.050 & 0.062 & 0.074 & 0.083 & 0.090 & 0.092 & 0.090 & 0.083 & 0.074 & 0.062 & 0.050 & 0.038 & 0.027 & 0.019 & 0.012 & 0.008 & 0.005 & 1.000 \\
\hline \multicolumn{23}{|l|}{ Herb layer } \\
\hline $\begin{array}{l}\text { Calamagros } \\
\text { tis villosa }\end{array}$ & 15 & 0.002 & 0.003 & 0.006 & 0.011 & 0.018 & 0.027 & 0.040 & 0.054 & 0.070 & 0.084 & 0.095 & 0.101 & 0.101 & 0.095 & 0.084 & 0.070 & 0.054 & 0.040 & 0.027 & 0.018 & 1.000 \\
\hline $\begin{array}{l}\text { Vaccinium } \\
\text { myrtillus }\end{array}$ & 37 & 0.005 & 0.008 & 0.012 & 0.019 & 0.027 & 0.038 & 0.050 & 0.062 & 0.074 & 0.083 & 0.090 & 0.092 & 0.090 & 0.083 & 0.074 & 0.062 & 0.050 & 0.038 & 0.027 & 0.019 & 1.000 \\
\hline $\begin{array}{l}\text { Deschampsi } \\
\text { a flexuosa }\end{array}$ & 37 & 0.012 & 0.019 & 0.027 & 0.037 & 0.049 & 0.061 & 0.073 & 0.083 & 0.089 & 0.091 & 0.089 & 0.083 & 0.073 & 0.061 & 0.049 & 0.037 & 0.027 & 0.019 & 0.012 & 0.008 & 1.000 \\
\hline $\begin{array}{l}\text { Galium } \\
\text { saxatile }\end{array}$ & 15 & 0.012 & 0.019 & 0.027 & 0.037 & 0.049 & 0.061 & 0.073 & 0.083 & 0.089 & 0.091 & 0.089 & 0.083 & 0.073 & 0.061 & 0.049 & 0.037 & 0.027 & 0.019 & 0.012 & 0.008 & 1.000 \\
\hline
\end{tabular}




\subsubsection{0:45:45}

\begin{tabular}{|c|c|c|c|c|c|c|c|c|c|c|c|c|c|c|c|c|c|c|c|c|c|c|}
\hline $\begin{array}{l}\text { Trientalis } \\
\text { europaea }\end{array}$ & 15 & 0.006 & 0.011 & 0.017 & 0.027 & 0.039 & 0.054 & 0.069 & 0.083 & 0.094 & 0.100 & 0.100 & 0.094 & 0.083 & 0.069 & 0.054 & 0.039 & 0.027 & 0.017 & 0.011 & 0.006 & 1.000 \\
\hline $\begin{array}{l}\text { Dryopteris } \\
\text { dilatata }\end{array}$ & 0.1 & 0.000 & 0.000 & 0.000 & 0.001 & 0.002 & 0.006 & 0.013 & 0.025 & 0.044 & 0.068 & 0.095 & 0.118 & 0.132 & 0.132 & 0.118 & 0.095 & 0.068 & 0.044 & 0.025 & 0.013 & 1.000 \\
\hline $\begin{array}{l}\text { Maianthemu } \\
m \text { bifolium }\end{array}$ & 0.1 & 0.006 & 0.011 & 0.017 & 0.027 & 0.039 & 0.054 & 0.069 & 0.083 & 0.094 & 0.100 & 0.100 & 0.094 & 0.083 & 0.069 & 0.054 & 0.039 & 0.027 & 0.017 & 0.011 & 0.006 & 1.000 \\
\hline $\begin{array}{l}\text { pteridium } \\
\text { aquilinum }\end{array}$ & 0.1 & 0.000 & 0.000 & 0.000 & 0.000 & 0.000 & 0.001 & 0.003 & 0.009 & 0.022 & 0.045 & 0.078 & 0.116 & 0.148 & 0.160 & 0.148 & 0.116 & 0.078 & 0.045 & 0.022 & 0.009 & 1.000 \\
\hline $\begin{array}{l}\text { Luzula } \\
\text { pilosa }\end{array}$ & 0.1 & 0.006 & 0.011 & 0.017 & 0.027 & 0.039 & 0.054 & 0.069 & 0.083 & 0.094 & 0.100 & 0.100 & 0.094 & 0.083 & 0.069 & 0.054 & 0.039 & 0.027 & 0.017 & 0.011 & 0.006 & 1.000 \\
\hline \multicolumn{23}{|l|}{ Moss layer } \\
\hline $\begin{array}{l}\text { Dicranum } \\
\text { scoparium }\end{array}$ & 0.1 & 0.018 & 0.027 & 0.040 & 0.054 & 0.070 & 0.084 & 0.095 & 0.101 & 0.101 & 0.095 & 0.084 & 0.070 & 0.054 & 0.040 & 0.027 & 0.018 & 0.011 & 0.006 & 0.003 & 0.002 & 1.000 \\
\hline $\begin{array}{l}\text { Barbilophozi } \\
\text { a floerkei }\end{array}$ & 0.1 & & & & & & & & & & & & & & & & & & & & & \\
\hline $\begin{array}{l}\text { Pleurozium } \\
\text { schreberi }\end{array}$ & 3 & 0.020 & 0.027 & 0.035 & 0.043 & 0.052 & 0.060 & 0.067 & 0.073 & 0.077 & 0.078 & 0.077 & 0.073 & 0.067 & 0.060 & 0.052 & 0.043 & 0.035 & 0.027 & 0.020 & 0.015 & 1.000 \\
\hline $\begin{array}{l}\text { Lophocolea } \\
\text { heterophylla }\end{array}$ & 0.10 & 0.000 & 0.000 & 0.000 & 0.000 & 0.000 & 0.001 & 0.005 & 0.016 & 0.043 & 0.091 & 0.151 & 0.193 & 0.193 & 0.151 & 0.091 & 0.043 & 0.016 & 0.005 & 0.001 & 0.000 & 1.000 \\
\hline $\begin{array}{l}\text { Dicranum } \\
\text { majus }\end{array}$ & 15 & 0.000 & 0.000 & 0.000 & 0.000 & 0.001 & 0.003 & 0.009 & 0.022 & 0.044 & 0.078 & 0.116 & 0.147 & 0.160 & 0.147 & 0.116 & 0.078 & 0.044 & 0.022 & 0.009 & 0.003 & 1.000 \\
\hline
\end{tabular}


Table 6. Calculation of the expected value of the soil moisture index of the ICP Forests LII-1605 site (Großer

Eisenberg, Thuringian Forest, Germany) in 1960 from the probability densities (pdf) of the occurring plant species

over 20 classes of the soil moisture index

\begin{tabular}{|c|c|c|c|c|c|c|c|c|c|c|c|c|c|c|c|c|c|c|c|c|c|c|}
\hline Species & $\begin{array}{c}\text { Cov } \\
\%\end{array}$ & 0.25 & 0.75 & 1.25 & 1.75 & 2.25 & 2.75 & 3.25 & 3.75 & 4.25 & 4.75 & 5.25 & 5.75 & 6.25 & 6.75 & 7.25 & 7.75 & 8.25 & 8.75 & 9.25 & 9.75 & $\begin{array}{l}\text { Sum } \\
\text { Line }\end{array}$ \\
\hline \multicolumn{23}{|l|}{$\begin{array}{l}\text { Upper tree } \\
\text { layer }\end{array}$} \\
\hline Picea abies & 15 & & & & & & & & & & & & & & & & & & & & & \\
\hline \multicolumn{23}{|l|}{$\begin{array}{l}\text { Lower tree } \\
\text { layer }\end{array}$} \\
\hline \multicolumn{23}{|c|}{\begin{tabular}{l|l} 
Picea abies & 60 \\
\end{tabular}} \\
\hline \multicolumn{23}{|l|}{ Shrub layer } \\
\hline Picea abies & 87 & 0.333 & 0.539 & 0.836 & 1.248 & 1.788 & 2.463 & 3.259 & 4.143 & 5.060 & 5.938 & 6.695 & 7.253 & 7.549 & 7.549 & 7.253 & 6.695 & 5.938 & 5.060 & 4.143 & 3.259 & 87.000 \\
\hline $\begin{array}{l}\text { Sorbus } \\
\text { aucuparia }\end{array}$ & 0.01 & 0.000 & 0.000 & 0.000 & 0.000 & 0.000 & 0.001 & 0.001 & 0.001 & 0.001 & 0.001 & 0.001 & 0.001 & 0.001 & 0.000 & 0.000 & 0.000 & 0.000 & 0.000 & 0.000 & 0.000 & 0.010 \\
\hline $\begin{array}{l}\text { sylvatica } \\
\text { fagus }\end{array}$ & 0.1 & 0.002 & 0.003 & 0.004 & 0.005 & 0.006 & 0.007 & 0.008 & 0.009 & 0.009 & 0.009 & 0.008 & 0.007 & 0.006 & 0.005 & 0.004 & 0.003 & 0.002 & 0.001 & 0.001 & 0.000 & 0.100 \\
\hline \multicolumn{23}{|l|}{ Herb layer } \\
\hline $\begin{array}{l}\text { Calamagrosti } \\
\text { s villosa }\end{array}$ & 15 & 0.025 & 0.049 & 0.091 & 0.160 & 0.264 & 0.409 & 0.595 & 0.814 & 1.045 & 1.261 & 1.428 & 1.521 & 1.521 & 1.428 & 1.261 & 1.045 & 0.814 & 0.595 & 0.409 & 0.264 & 15.000 \\
\hline $\begin{array}{l}\text { Vaccinium } \\
\text { myrtillus }\end{array}$ & 37 & 0.171 & 0.288 & 0.460 & 0.700 & 1.013 & 1.397 & 1.832 & 2.288 & 2.720 & 3.078 & 3.314 & 3.397 & 3.314 & 3.078 & 2.720 & 2.288 & 1.832 & 1.397 & 1.013 & 0.700 & 37.000 \\
\hline $\begin{array}{l}\text { Deschampsi } \\
\text { a flexuosa }\end{array}$ & 37 & 0.456 & 0.694 & 1.005 & 1.386 & 1.818 & 2.271 & 2.699 & 3.054 & 3.289 & 3.371 & 3.289 & 3.054 & 2.699 & 2.271 & 1.818 & 1.386 & 1.005 & 0.694 & 0.456 & 0.285 & 37.000 \\
\hline $\begin{array}{l}\text { Galium } \\
\text { saxatile }\end{array}$ & 15 & 0.185 & 0.281 & 0.408 & 0.562 & 0.737 & 0.921 & 1.094 & 1.238 & 1.333 & 1.367 & 1.333 & 1.238 & 1.094 & 0.921 & 0.737 & 0.562 & 0.408 & 0.281 & 0.185 & 0.116 & 15.000 \\
\hline
\end{tabular}




\subsubsection{0:45:45}

\begin{tabular}{|c|c|c|c|c|c|c|c|c|c|c|c|c|c|c|c|c|c|c|c|c|c|c|}
\hline $\begin{array}{l}\text { Trientalis } \\
\text { europaea }\end{array}$ & 15 & 0.090 & 0.158 & 0.261 & 0.404 & 0.588 & 0.804 & 1.033 & 1.246 & 1.412 & 1.503 & 1.503 & 1.412 & 1.246 & 1.033 & 0.804 & 0.588 & 0.404 & 0.261 & 0.158 & 0.090 & 15.000 \\
\hline $\begin{array}{l}\text { Dryopteris } \\
\text { dilatata }\end{array}$ & 0.1 & 0.000 & 0.000 & 0.000 & 0.000 & 0.000 & 0.001 & 0.001 & 0.003 & 0.004 & 0.007 & 0.009 & 0.012 & 0.013 & 0.013 & 0.012 & 0.009 & 0.007 & 0.004 & 0.003 & 0.001 & 0.100 \\
\hline $\begin{array}{l}\text { Maianthemu } \\
m \text { bifolium }\end{array}$ & 0.1 & 0.001 & 0.001 & 0.002 & 0.003 & 0.004 & 0.005 & 0.007 & 0.008 & 0.009 & 0.010 & 0.010 & 0.009 & 0.008 & 0.007 & 0.005 & 0.004 & 0.003 & 0.002 & 0.001 & 0.001 & 0.100 \\
\hline $\begin{array}{l}\text { pteridium } \\
\text { aquilinum }\end{array}$ & 0.1 & 0.000 & 0.000 & 0.000 & 0.000 & 0.000 & 0.000 & 0.000 & 0.001 & 0.002 & 0.004 & 0.008 & 0.012 & 0.015 & 0.016 & 0.015 & 0.012 & 0.008 & 0.004 & 0.002 & 0.001 & 0.100 \\
\hline Luzula pilosa & 0.1 & 0.001 & 0.001 & 0.002 & 0.003 & 0.004 & 0.005 & 0.007 & 0.008 & 0.009 & 0.010 & 0.010 & 0.009 & 0.008 & 0.007 & 0.005 & 0.004 & 0.003 & 0.002 & 0.001 & 0.001 & 0.100 \\
\hline \multicolumn{23}{|l|}{ Moss layer } \\
\hline $\begin{array}{l}\text { Dicranum } \\
\text { scoparium }\end{array}$ & 0.1 & 0.002 & 0.003 & 0.004 & 0.005 & 0.007 & 0.008 & 0.010 & 0.010 & 0.010 & 0.010 & 0.008 & 0.007 & 0.005 & 0.004 & 0.003 & 0.002 & 0.001 & 0.001 & 0.000 & 0.000 & 0.100 \\
\hline $\begin{array}{l}\text { Barbilophozi } \\
\text { a floerkei }\end{array}$ & 0.1 & & & & & & & & & & & & & & & & & & & & & \\
\hline $\begin{array}{l}\text { Pleurozium } \\
\text { schreberi }\end{array}$ & 3 & 0.061 & 0.081 & 0.104 & 0.129 & 0.155 & 0.180 & 0.202 & 0.219 & 0.230 & 0.234 & 0.230 & 0.219 & 0.202 & 0.180 & 0.155 & 0.129 & 0.104 & 0.081 & 0.061 & 0.045 & 3.000 \\
\hline $\begin{array}{l}\text { Lophocolea } \\
\text { heterophylla }\end{array}$ & 0.10 & 0.000 & 0.000 & 0.000 & 0.000 & 0.000 & 0.000 & 0.000 & 0.002 & 0.004 & 0.009 & 0.015 & 0.019 & 0.019 & 0.015 & 0.009 & 0.004 & 0.002 & 0.000 & 0.000 & 0.000 & 0.100 \\
\hline $\begin{array}{l}\text { Dicranum } \\
\text { majus }\end{array}$ & 15 & 0.000 & 0.000 & 0.001 & 0.004 & 0.014 & 0.048 & 0.135 & 0.324 & 0.666 & 1.167 & 1.740 & 2.212 & 2.397 & 2.212 & 1.740 & 1.167 & 0.666 & 0.324 & 0.135 & 0.048 & 15.000 \\
\hline $\begin{array}{l}\text { column } \\
\text { product }\end{array}$ & & $\begin{array}{l}2.9 \mathrm{E}- \\
50\end{array}$ & $\begin{array}{l}3.9 \mathrm{E}- \\
44\end{array}$ & $\begin{array}{l}1.3 \mathrm{E}- \\
38\end{array}$ & \begin{tabular}{|l|}
$1.2 \mathrm{E}-$ \\
33 \\
\end{tabular} & $\begin{array}{l}2.5 \mathrm{E}- \\
29\end{array}$ & $\begin{array}{l}1.4 \mathrm{E}- \\
25\end{array}$ & $\begin{array}{l}1.9 \mathrm{E}- \\
22\end{array}$ & $\begin{array}{l}6.8 \mathrm{E}- \\
20\end{array}$ & $\begin{array}{l}6.0 \mathrm{E}- \\
18 \\
\end{array}$ & $\begin{array}{l}1.4 \mathrm{E}- \\
16 \\
\end{array}$ & \begin{tabular}{|l|}
$7.7 \mathrm{E}-$ \\
16
\end{tabular} & \begin{tabular}{|l|}
$1.1 \mathrm{E}-$ \\
15
\end{tabular} & \begin{tabular}{|l|}
$4.0 \mathrm{E}-$ \\
16
\end{tabular} & \begin{tabular}{|l|}
$3.7 \mathrm{E}-$ \\
17
\end{tabular} & \begin{tabular}{|l|}
$8.5 \mathrm{E}-$ \\
19
\end{tabular} & $\begin{array}{l}5.0 \mathrm{E}- \\
21\end{array}$ & $\begin{array}{l}7.4 \mathrm{E}- \\
24\end{array}$ & $\begin{array}{l}2.8 \mathrm{E}- \\
27\end{array}$ & $\begin{array}{l}2.6 \mathrm{E}- \\
31\end{array}$ & $\begin{array}{l}6.2 \mathrm{E}- \\
36\end{array}$ & $\begin{array}{l}2.4 \mathrm{E}- \\
15\end{array}$ \\
\hline $\begin{array}{l}\text { Column } \\
\text { product. } \\
\text { standardized } \\
\text { (pdf) }\end{array}$ & & 0.00 & 0.00 & 0.00 & 0.00 & 0.00 & 0.00 & 0.00 & 0.00 & 0.00 & 0.06 & 0.31 & 0.45 & 0.16 & 0.01 & 0.00 & 0.00 & 0.00 & 0.00 & 0.00 & 0.00 & 1.00 \\
\hline $\begin{array}{l}\text { pdf * soil } \\
\text { moisture } \\
\text { class value }\end{array}$ & & 0.00 & 0.00 & 0.00 & 0.00 & 0.00 & 0.00 & 0.00 & 0.00 & 0.01 & 0.26 & 1.65 & 2.59 & 1.02 & 0.10 & 0.00 & 0.00 & 0.00 & 0.00 & 0.00 & 0.00 & 5.6 \\
\hline
\end{tabular}




\section{$2 \quad 2.1 .5$ Indicator of adaptability to changing environmental conditions}

4 As an indicator of adaptability to changing, unpredictable environmental

5 conditions, the percentage similarity of the current proportions of tree species

6 with the spectrum of natural site tree species (Jenssen \& Hofmann 2003) is used:

${ }_{7} \quad P=\sum_{i} \min \left(P_{i}, P_{i}^{\max }\right)$

8 The $p_{i}$ denote the percentage amount shares of the tree species indexed with $\mathrm{i}$

9 for the current stocking on the area to be valuated, whereby the quantity shares

10 are summed over several possibly existing tree layers and set to $100 \%$ :

11

$$
\sum_{i} P_{i}=100 \%
$$

12 The $P_{i}^{\max }$ describe the maximum percentage areas of natural site-specific tree

13 species that are not exceeded in the course of self-organized development

14 stages under the respective site conditions (explanations in Jenssen et al. 2013,

15 Chapter 4). 
17 The $P_{i}^{\max }$ were determined on the basis of the knowledge of the natural

18 distribution and the site requirements as well as the growth and competition

19 behaviour of the native tree species for the different ecosystem types and

20 documented in the data sheets of the reference conditions (Jenssen et al. 2019

21 c). The $p_{i}$ are determined from the actual cover values of the natural site-specific

22 tree species on the receiving area.

24 Figure 5. Basic scheme for determining the similarity of the current tree species

25 composition with the spectrum of natural tree species

27 For a raw humus pine beech forest (Eb-4n-B2), for example, the data sheet for

28 reference conditions (Jenssen et al. 2019 c) gives $80 \%$ for the red beech, $40 \%$

29 for the grape oak, $30 \%$ each for sand birch and pine and $5 \%$ for the mountain

30 ash as the maximum proportions of natural site-specific tree species in self-

31 organised development stages. At present, $70 \%$ pine, $20 \%$ red beech, $5 \%$

32 grape oak and $5 \%$ sand birch are found on a vegetation survey area assigned to

33 this reference condition. The indicator is thus calculated as follows 
$35 P=\min (70 \%, 30 \%)+\min (20 \%, 80 \%)+\min (5 \%, 40 \%)+\min (5 \%, 30 \%)=60 \%$

37 The current proportions of tree species are therefore to $60 \%$ similar to the

38 spectrum of natural site tree species, i.e. those tree species which are not

39 exceeded in the course of self-organised developmental stages (in contrast to

40 the classical definition of potential natural vegetation (PNV), the spectrum covers

41 not only the main stages but also temporary intermediate forest stages) at this

42 site. Despite excessive amounts of pine, the stock still has sufficient potential to

43 adapt to possibly changing environmental conditions through self-organised

44 development.

46 Example: ICP Forests Level II site 1605 (Großer Eisenberg, Thuringian Forest,

47 Germany)

49 For ecosystem type C4-6d-B1, the data sheet of reference states (Jenssen et al.

502019 c) gives the maximum proportions of natural site-specific tree species in

51 self-organised development stages as $100 \%$ for spruce, $5 \%$ for mountain ash, 2 
$52 \%$ for bog birch and $5 \%$ for silver fir as maximum proportions of natural site tree

53 species. In 1960 and in all other monitoring years, $100 \%$ spruce was found on

54 the vegetation survey area. Thus the indicator is calculated to $P=\min (100 \%$,

$55 \quad 100 \%)=100 \%$. The current proportions of tree species are therefore to $100 \%$

56 similar to the spectrum of natural site tree species, i.e. those tree species which

57 are not exceeded in the course of self-organised development stages at this site.

$59 \quad 2.2$ Classification of ecosystem integrity

61 The analysis and estimation of ecosystem conditions and their development over

62 time is basically carried out by comparison with a functionally and structurally

63 determined historical reference condition (Jenssen et al. 2013, 2019 c; Schröder

64 et al. 2015, 2019). The change in ecosystem integrity is to be classified as higher

65 the more the status parameters deviate from those of the respective ecosystem

66 type-specific reference status.

67 
68 To classify ecosystem integrity, a distinction is made between 5 levels in

69 comparison with the reference state, namely on three levels (Figure 6):

70 1. Deviations from the reference situation for individual indicators,

71 2. Deviations from the reference state for individual functions (based on

72 indicators),

73 3. Changes in ecosystem integrity across functions for the ecosystem type

$74 \quad$ under consideration.

75

$76 \quad$ Figure 6. Scheme for classifying ecosystem integrity

77

78 The deviations between the interval limits of the ecosystem-specific reference

79 condition and the lower or upper limit of the ecosystem -specific total span are

80 subdivided into the levels very low (= within the reference span) and low,

81 medium, high and very high. The classifications for a total of 13 indicators

82 assigned to 6 ecosystem functions are based on the principles presented in

83 Table 7.

84 
85 Table 7. Definition of the deviation levels from the reference state

\begin{tabular}{|c|c|c|c|c|c|c|}
\hline \multirow[t]{2}{*}{ Indicator } & \multirow[t]{2}{*}{$\begin{array}{l}\text { Total } \\
\text { span }\end{array}$} & \multicolumn{5}{|c|}{$\begin{array}{l}\text { Classification of deviations from the } \\
\text { reference condition }\end{array}$} \\
\hline & & very low & low & $\begin{array}{l}\text { medi } \\
\text { um }\end{array}$ & high & $\begin{array}{l}\text { very } \\
\text { high }\end{array}$ \\
\hline \multicolumn{7}{|c|}{ Habitat function } \\
\hline $\begin{array}{l}\text { Kullback } \\
\text { Distance }\end{array}$ & $0,0-4,0$ & $\begin{array}{l}\text { Range } \\
\text { between } 0 \\
\text { and } \\
\text { respective } \\
\text { maxi-mal } \\
\text { Kullback } \\
\text { distance }\end{array}$ & \multicolumn{4}{|c|}{$\begin{array}{l}\text { Quartering of the remaining } \\
\text { interval }\end{array}$} \\
\hline $\begin{array}{l}\text { Percentage } \\
\text { similarity of } \\
\text { plant species } \\
\text { quantity } \\
\text { distribution }\end{array}$ & $0-100 \%$ & $\begin{array}{l}\text { Interval from } \\
100 \% \text { to } \\
\text { minimum } \\
\text { percentage } \\
\text { similarity }\end{array}$ & \multicolumn{4}{|c|}{$\begin{array}{l}\text { Quartering of the remaining } \\
\text { interval }\end{array}$} \\
\hline
\end{tabular}

\begin{tabular}{|c|c|c|c|}
\hline \multicolumn{4}{|c|}{ Net primary production } \\
\hline $\begin{array}{l}\text { Average net } \\
\text { primary } \\
\text { production }\end{array}$ & $\begin{array}{l}0-\infty \text { t } \\
\text { TS/ha }\end{array}$ & $\begin{array}{l}\text { Values above } \\
\text { the average } \\
\text { net primary } \\
\text { production of } \\
\text { tree wood }\end{array}$ & $\begin{array}{l}\text { Quartering of the remaining } \\
\text { interval }\end{array}$ \\
\hline \multicolumn{4}{|c|}{ Carbon storage } \\
\hline carbon stock & $0-t / h a \infty$ & $\begin{array}{l}\text { Values above } \\
\text { the individual } \\
\text { value for the } \\
\text { mean carbon } \\
\text { stock (or } \\
\text { mean value } \\
\text { for ranges) }\end{array}$ & $\begin{array}{l}\text { Quartering of the remaining } \\
\text { interval }\end{array}$ \\
\hline
\end{tabular}




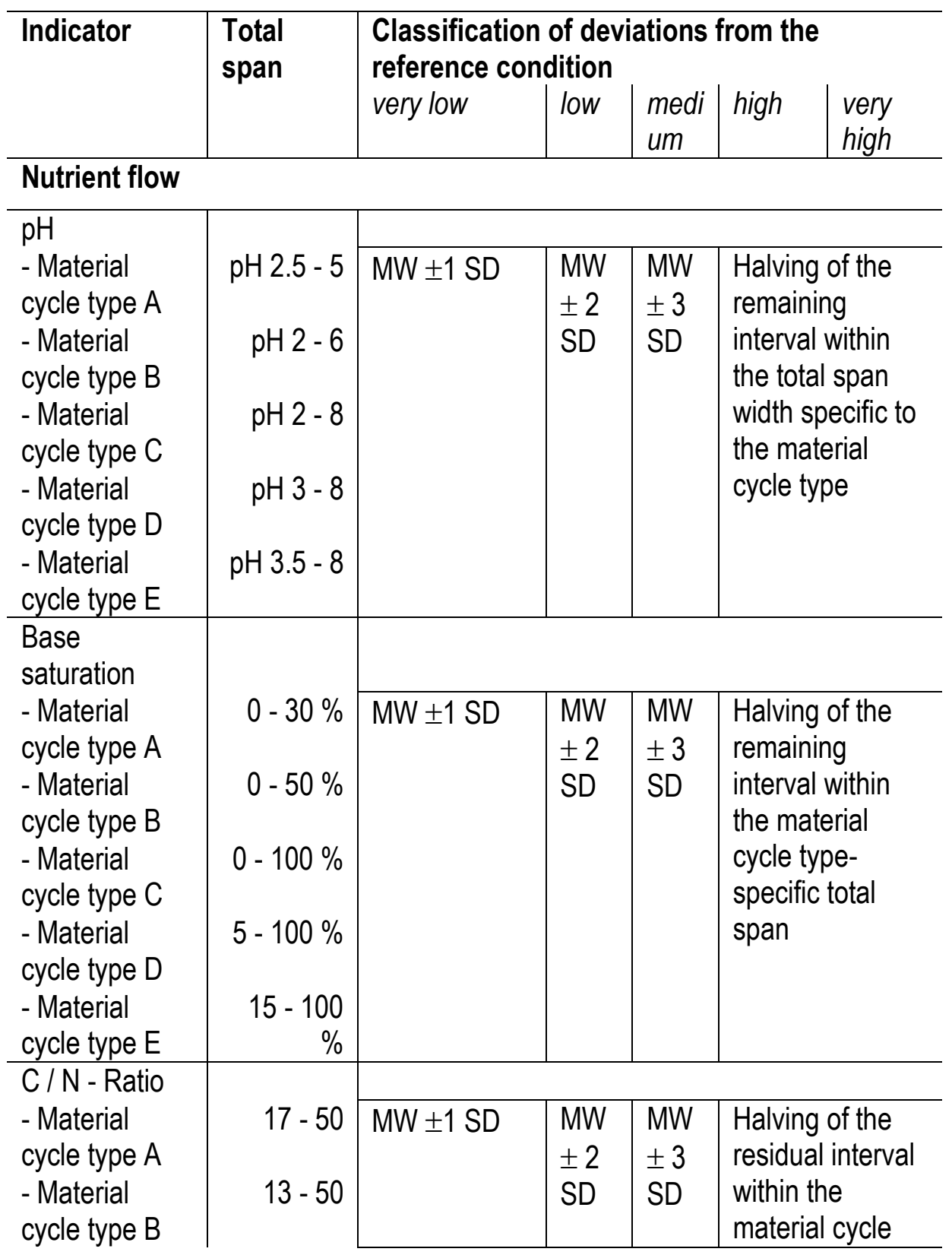




\begin{tabular}{|c|c|c|c|c|c|c|}
\hline \multirow[t]{2}{*}{ Indicator } & \multirow[t]{2}{*}{$\begin{array}{l}\text { Total } \\
\text { span }\end{array}$} & \multicolumn{5}{|c|}{$\begin{array}{l}\text { Classification of deviations from the } \\
\text { reference condition }\end{array}$} \\
\hline & & very low & low & $\begin{array}{l}\text { medi } \\
\text { um }\end{array}$ & high & $\begin{array}{l}\text { very } \\
\text { high }\end{array}$ \\
\hline $\begin{array}{l}\text { - Material } \\
\text { cycle type C } \\
\text { - Material } \\
\text { cycle type D } \\
\text { - Material } \\
\text { cycle type E }\end{array}$ & $\begin{array}{l}6-50 \\
6-36 \\
6-26\end{array}$ & & & & \multicolumn{2}{|c|}{$\begin{array}{l}\text { type-specific } \\
\text { total span }\end{array}$} \\
\hline \multicolumn{7}{|c|}{ Leaf / needle mirror values } \\
\hline $\begin{array}{l}\text { - Nitrate } \\
\text { - Phosphor } \\
\text { - Potassium } \\
\text { - Calcium } \\
\text { - Magnesium }\end{array}$ & $\begin{array}{c}0-4.0 \% \\
\text { by weight } \\
0-0.6 \% \\
\text { by weight } \\
0-2.5 \% \\
\text { by weight } \\
0-2.65 \% \\
\text { by weight } \\
0-0.6 \% \\
\text { by weight }\end{array}$ & $\mathrm{MW} \pm 1 \mathrm{SD}$ & $\begin{array}{l}\text { MW } \\
\pm 2 \\
\text { SD }\end{array}$ & $\begin{array}{l}\text { MW } \\
\pm 3 \\
\text { SD }\end{array}$ & \multicolumn{2}{|c|}{$\begin{array}{l}\text { Halving of the } \\
\text { remaining } \\
\text { interval within } \\
\text { the substance- } \\
\text { specific total } \\
\text { span width }\end{array}$} \\
\hline \multicolumn{7}{|l|}{ Water flow } \\
\hline $\begin{array}{l}\text { Soil moisture } \\
\text { index } \\
\text { according to } \\
\text { Hofmann } \\
(20002)\end{array}$ & $\begin{array}{r}0(= \\
\text { extremely } \\
\text { dry) to } 11 \\
(= \\
\text { flooded })\end{array}$ & $\mathrm{MW} \pm 1 \mathrm{SD}$ & $\begin{array}{l}\text { MW } \\
\pm 2 \\
\text { SD }\end{array}$ & $\begin{array}{l}\text { MW } \\
\pm 3 \\
\text { SD }\end{array}$ & \multicolumn{2}{|c|}{$\begin{array}{l}\text { Halving of the } \\
\text { remaining } \\
\text { interval within } \\
\text { the total span } \\
\text { width }\end{array}$} \\
\hline \multicolumn{7}{|c|}{ Adaptation to changing environmental conditions } \\
\hline $\begin{array}{l}\text { Similarity of } \\
\text { tree species } \\
\text { composition }\end{array}$ & $100-0 \%$ & $100-60 \%$ & $\begin{array}{l}<60 \\
- \\
45 \%\end{array}$ & $\begin{array}{l}<45 \\
- \\
30 \%\end{array}$ & $\begin{array}{l}<30- \\
15 \%\end{array}$ & \begin{tabular}{|l|}
$<15-$ \\
$0 \%$
\end{tabular} \\
\hline
\end{tabular}


87 The variance levels for the indicators of habitat function, net primary production

88 and carbon sequestration are based on the historically determined reference

89 span and a quartering of the residual interval within the total span. For the

90 nutrient balance indicators whose reference range is defined by the respective

91 ecosystem mean value of \pm the simple standard deviation (see above): indicator

92 value models for calculating the $\mathrm{C} / \mathrm{N}$ and $\mathrm{pH}$ the topsoil, the base saturation of

93 the topsoil and the moisture index of the topsoil), are assigned low and medium

94 with values into the ranges smaller than 2 or 3 times the standard deviation. The

95 steps high and very high were defined by halving the remaining intervals within

96 the overall spans specific to the material or material cycle type. For ecosystem

97 types where the triple standard deviation is already outside the total span, the

98 deviation steps high and very high are omitted (e.g. for the pH of the Moder-

99 Tannen-Buchen-Bergwald (D2-6d-C2; Moder fir and beech forests of the

100 montane level), or the base saturation of the Magerrohhumus-Sand-Kiefernwald

101 (Ed-2n-A2; Sandy meager-raw-humus pine forests). According to Jenssen \&

102 Hofmann (2003), near-natural stands are characterised by values of $60-100 \%$.

103 This span is used as a reference (= very small). The deviation interval below 60 
$104 \%$ is quartered and distributed equally for all ecosystem types to the levels low (= $10559-45 \%)$, medium (= 44-30\%), high (= 15-29 \%) and very high (= 0-14 \%).

107 In the case of ecological functions, which are described by only one indicator (net 108 primary production, carbon storage, water flow, adaptability), the classification is 109 directly linked to the assessment of the individual indicators. For functions with

110 several assigned indicators (habitat, nutrient flow), the individual estimates are

111 aggregated via the modal value (level 2 in Figure 6). The modal value also

112 provides good orientation for the overall functional classification of changes in

113 ecosystem integrity, with all criteria being considered equally. For the

114 interpretation, the meanings of the 5 levels of deviation and change are

115 described in Table 8.

117 Table 8. Levels of deviation from ecosystem type reference states and levels of 118 change of ecosystem integrity

\begin{tabular}{l|l}
\hline Level & Meaning \\
\hline
\end{tabular}




\begin{tabular}{l|l}
\hline Level & Meaning \\
\hline very low & $\begin{array}{l}\text { The values of the indicators habitat function, net primary production } \\
\text { and carbon storage correspond to those of the reference range. } \\
\text { For the respective ecosystem type there are also no or only very } \\
\text { minor changes in the values for the physical-chemical conditions } \\
\text { (nutrient flow, water flow) compared to the values that characterise } \\
\text { the historical reference condition 1961-1990. The similarity of the } \\
\text { current tree species composition with the spectrum of natural site- } \\
\text { specific tree species is very high. }\end{array}$ \\
\hline low & $\begin{array}{l}\text { The indicators for habitat function, net primary production and } \\
\text { carbon storage show small deviations from the historical reference } \\
\text { values. The physical-chemical conditions also deviate only slightly } \\
\text { from the values of the reference type. There is a high similarity } \\
\text { between the current tree species composition and the spectrum of } \\
\text { natural site-specific tree species. }\end{array}$ \\
\hline medium & $\begin{array}{l}\text { The values of ecosystem function indicators differ moderately from } \\
\text { those normally associated with the historically determined } \\
\text { reference status. The values give indications of moderate } \\
\text { deviations and show significantly stronger interference than was } \\
\text { the case under historical conditions. There is a moderate similarity } \\
\text { between the current tree species composition and the spectrum of } \\
\text { natural site-specific tree species. }\end{array}$ \\
\hline high & $\begin{array}{l}\text { Ecosystem conditions where indicators point to major changes and } \\
\text { differ significantly from those normally associated with the } \\
\text { reference status. There is little similarity between the current tree } \\
\text { species composition and the spectrum of natural site-specific tree } \\
\text { species. }\end{array}$ \\
\hline $\begin{array}{l}\text { Ecosystem conditions in which the indicators point to very strong } \\
\text { changes and deviate very strongly from the historical reference } \\
\text { condition. There is very little similarity between the current tree } \\
\text { species composition and the spectrum of natural site-specific tree } \\
\text { species. }\end{array}$ \\
\hline
\end{tabular}


120 With regard to the interpretation of detected deviations from the reference

121 condition, various threshold values can be used to derive different needs for

122 action on the basis of Mitchell et al. (2014) (Figure 7). Under the simplified

123 assumption of a linear decrease in ecosystem integrity beyond the characteristic

124 range of the reference state, continued measures of environmental monitoring

125 are recommended from the stage low, at the latest from the stage medium, if the

126 temporal trend indicates an increase in deviations from the reference state.

127 Management measures are recommended from the high level onwards, at which

128 conditions outside the ecosystem-specific, natural variability are given (here:

129 mean value of \pm three times standard deviation). Appropriate concretizations can

130 be justified with the changes identified at indicator, function and/or ecosystem

131 level.

132

133 Figure 7. Classification of ecosystem integrity and derivation of needs for action 134 (based on Mitchell et al. 2014)

135

$136 \quad$ 2.2.1 Site-specific classification 
138 The assessment forms for 61 forest and forest ecosystem types (Jenssen et al.

1392019 b) can be used to classify ecosystem integrity at individual sites.

141 A. Deviation levels for the indicators

143 At the first level, it is assumed that the ecosystem type was determined by

144 means of a determination key or computer-aided comparison of a vegetation

145 survey with the reference conditions documented in Jenssen et al. (2019 a, 2019

146 c) (Schröder et al. 2019, vol. 2, chapter 2) and that the characteristics of the

147 indicators for the 6 ecosystem functions (Section 2.1) were determined. On this

148 basis, the deviation from the respective reference status is classified using the 149 assessment sheet specified for the ecosystem type identified (level 1 in Figure 150 6). 
152 Example: ICP Forests Level II site 1605 (Thuringian Forest, Germany) - "base 153 saturation" at the Rohhumus-Fichten-Hochbergwald (C4-6d-B1; Raw-humus 154 spruce forest on the altimontane level; Figure 7)

156 For the Rohhumus-Fichten-Hochbergwald (C4-6d-B1; Raw-humus spruce forest

157 on the altimontane level) at ICP Forests Level II site 1605 in the Thuringian

158 Forest, the interval of the reference condition is $12.9-19.7 \%$. A base saturation

159 value of $25 \%$ was estimated on the basis of vegetation cover (Section 2.1.4.2).

160 The deviation from the reference condition is classified as 'medium' on the basis

161 of the rules documented in the evaluation sheet. Continuous observation of the

162 examination area is recommended.

163

164 B. Deviation levels for the functions

165

166 In the case of ecosystem functions (level 2 in Figure 6), deviations from the

167 reference status are determined by evaluating the characteristics of the assigned

168 indicators. Since net primary production, carbon storage, water flow and 
169 adaptation to changing environmental conditions are each described by a

170 singular indicator, the level of deviation for the function is identical to that of the

171 indicator. With regard to habitat function and nutrient flux, deviations from the

172 reference status are determined by aggregating the levels of deviation of the

173 associated indicators. Aggregation is done with the modal value providing good

174 orientation. All steps of the deviation from the reference condition are considered

175 equally. In principle, there can be several modes if several different deviation

176 levels occur with equal frequency. These multiple responses are carried along

177 until the final classification of integrity at the ecosystem level.

178

179 Example: ICP Forests Level II site 1605 (Großer Eisenberg, Thuringian Forest, 180 Germany) - "nutrient flow" at the Rohhumus-Fichten-Hochbergwald (C4-6d-B1;

181 Raw-humus spruce forest on the altimontane level; Figure 8)

182

183 For the Rohhumus-Fichten-Hochbergwald (C4-6d-B1; Raw-humus spruce forest

184 on the altimontane level) at the ICP Forests Level II 1605 site, the determined

185 values of the nutrient flow indicators result in different levels of deviations from 
186 the reference condition: high for the $\mathrm{pH}$, medium for the base saturation and very 187 high for the $\mathrm{C} / \mathrm{N}$ ratio, furthermore high ( $\mathrm{N}$ content needles), very low ( $\mathrm{P}$ content 188 needles), low ( $\mathrm{K}$ content needles), high (Ca content needles), medium (Mg 189 content needles). The aggregation of these 8 classifications results in an overall 190 deviation from the reference status high for the category nutrient flow at the level 191 of ecosystem functions, which indicates an increased need for countermeasures 192 (Figure 7).

193

194 C. Stages of change for ecosystem types

195

196 In a third step, the change in ecosystem integrity is classified across functions 197 (level 3 in Figure 6).

198

199 Example: ICP Forests Level II Location 1605 (Großer Eisenberg, Thuringian

200 Forest, Germany) - "Ecosystem Integrity" at the Rohhumus-Fichten-

201 Hochbergwald (C4-6d-B1; Raw-humus spruce forest on the altimontane level; 202 Figure 8) 
204 For the habitat function there are low or medium deviations from the reference 205 status, low deviations from the net primary production, very low deviations from 206 the C-storage, high deviations from the nutrient flow, low deviations from the 207 water flow and very low deviations from the reference status for the adaptability 208 to changing environmental conditions. This results in 2 denominations of the level 209 very low, 3 denominations of the level low, one denomination of the level medium 210 and one of the level high. The subsequent assessment leads to the classification

211 slight change in ecosystem integrity, in order to take into account the modal 212 value of the deviation from the reference condition in this example. With regard to 213 ecosystem integrity, continued observation of the study area is recommended.

215 Figure 8. Ecosystem integrity assessment sheet for a Raw-humus spruce forest 216 on the altimontane level (C4-6d-B1), ICP Forests Level II site 1605 (Großer 217 Eisenberg, Thuringian Forest, Germany) 
221 For an area-related classification of ecosystem integrity at the regional level, data 222 from vegetation-reception areas (e.g. in nature reserves) are often available or 223 in contrast to comparable soil data - can be collected with relatively little effort.

224 Deviations of current ecosystem conditions from the respective reference 225 conditions can be spatially generalised either on the basis of mapping of the 226 ecosystem types in the area under investigation or by division of the area into a 227 regular grid (e.g. $2.5 \mathrm{~km} \times 2.5 \mathrm{~km}$ ) in each case in connection with a 228 representative selection of vegetation survey areas as a sample.

230 Method 1: Classification of ecosystem integrity for mapped ecosystem types 231

232 In a first step, the quantification of the topsoil parameters from the vegetation 233 structures according to Section 2.1.4 is carried out. Based on the variances of 234 the reference data to the ecosystem types (Schröder et al. 2019), at least 5 235 vegetation relevés per ecosystem type are recommended for the regional level. 236 Using the wise values of the plant species, a site-specific classification of the 
237 deviations from the reference condition (1-very low, 2- low, 3- medium, 4- high,

2385 - very high) for the corresponding indicators of ecosystem integrity (Section

239 2.2.1) is then made for each vegetation survey area. Next, the ecosystem type-

240 specific median of the deviation levels is determined as the central tendency and

241 the maximum deviation. The medians are then aggregated via the modal value to

242 levels of deviation and change at the levels of ecological functions or ecosystems

243 (Section 2.2.1). The spatial transfer of the ecosystem-specific classifications

244 determined in this way can finally take place by allocation to the forest ecosystem

245 types mapped in the area concerned in the sense of an area interpolation.

247 Table 9. Deviation and ordination of shifting ecosystem integrity based on 6

248 indicators and 5 ecosystem types in the Kellerwald-Edersee National Park

249 (Hesse, federal state of Germany)

\begin{tabular}{l|l|l|l|l|l|l|l|l|l|l|l}
\hline Eco code & $\mathbf{n}$ & Kullback & Similarity & pH & V & C/N & DKF & HF & NF & WF & ESI \\
\hline D1-5n-C2 & 51 & very low & very low & low & very low & low & low & very low & low & low & low \\
\hline D1-6d-D1 & 8 & very low & low & low & medium & medium & medium & low & medium & medium & medium \\
\hline Eb-5n-C2 & 1 & very low & very low & low & low & low & low & very low & low & low & low \\
\hline Eb-5n-D10 7 & very low & very low & very low & very low & low & low & very low & very low & low & very low \\
\hline
\end{tabular}


250 Explanation: Ecosystem-specific variance and change levels based on the medians of

251 variance levels at indicator level; variance levels: very low, low, medium, high; HF =

252 habitat function, $\mathrm{NF}=$ nutrient flow, $\mathrm{WF}=$ water flow, $\mathrm{ESI}=$ changes in ecosystem

253 integrity.

255 Example: Kellerwald-Edersee National Park (Hesse, federal state of Germany)

257 For the area of the Kellerwald-Edersee National Park (Hesse, federal state of

258 Germany), an ecosystem type mapping on a scale of 1:5,000 and 70 vegetation

259 surveys for five different ecosystem types are available (Nickel et al. 2019 a)

260 (Table 9). After determining the topsoil parameters, for example for the

261 Braunmull-Buchen-Bergwald (D1-6d-D1; Brownmull beech forests of the

262 montane level), the value range of the moisture indicators (DKF) originating from

263 eight indicator value calculations is between 4.7 and 6.9. This results in eight

264 site-related classifications of the deviations from the reference condition between

265 very low and high (Figure 9). The median value as the central tendency is

266 medium. Together with the median values for the other indicators (here: Kullback

267 distance, similarity of species abundance distribution, $\mathrm{pH}$, base saturation, $\mathrm{C} / \mathrm{N}$ 
268 ratio), at the level of ecosystem functions the modal value results in the levels 269 low for habitat function, medium for nutrient flow and medium for water flow. The 270 modal value of these three deviation steps results in a mean change of

271 ecosystem integrity for the Braunmull-Buchen-Bergwald (D1-6d-D1; Brownmull

272 beech forests of the montane level). This results in the recommendation to

273 further monitor the development of ecosystem integrity of D1-6d-D1 in the

274 basement forest in the future, especially with regard to base saturation, $\mathrm{C} / \mathrm{N}$ ratio 275 and soil moisture.

276

277

278 Figure 9. Ecosystem type-specific classifications of deviations from the reference 279 condition for the moisture index in the Kellerwald-Edersee National Park (Hesse, 280 federal state of Germany)

281

282 Method 2: Classification of ecosystem integrity in an area grid 283

284 Alternatively, if no information on the spatial distribution of ecosystem types is 285 available for an area, the mean deviation from the reference state can be 
286 determined on the basis of an area grid. At a resolution of $2.5 \mathrm{~km} \times 2.5 \mathrm{~km}$ per

287 raster element, for example, at least two representative vegetation surveys are

288 recommended for evaluating indicators of soil condition. As in Method 1, a site-

289 specific classification of the deviations from the ecosystem-specific reference

290 condition for the indicators is first carried out for all the sites to be surveyed. For

291 each raster element the arithmetic mean of the deviation levels is determined,

292 also to show tendencies within the deviation level. On this basis, as in Method 1,

293 the medians are aggregated via the modal value to deviation and change levels

294 at the levels of ecological functions or ecosystems (Section 2.2.1). This finally

295 makes it possible to transfer the site-related classifications to the study area grid.

296

297 Figure 10. Grid-based classifications of the deviations from the reference state 298 for the soil moisture index in the Kellerwald-Edersee National Park (Hesse, 299 federal state of Germany)

300

301 Example: Kellerwald-Edersee National Park (Hesse, federal state of Germany) 302 
303 Based on the 70 vegetation surveys available for the Kellerwald-Edersee

304 National Park, the variance levels for five different ecosystem types and the

305 indicators of ecosystem integrity were determined. For the moisture index as an

306 indicator of water flow, there are 70 site-related classifications of deviations from

307 the reference condition between very low and high. For each grid, the mean

308 value of the deviation levels is calculated and used as the basis for the grid-

309 related classification (Figure 10). Information losses with regard to the variance

310 and the maximum deviation in each grid cell can be avoided by displaying the

311 classifications at the individual locations. The example of the Kellerwald (Nickel

312 et al. 2019 a, $2019 \mathrm{~b}$ shows that a higher spatial differentiation can be achieved

313 by using an area grid compared to the ecosystem type-specific classification,

314 since the area is strongly dominated by the Moder-Buchen-Bergwald (D1-5n-C2;

315 Moder beech forests of the montane level). Together with the variance levels for

316 the other indicators (e.g. Kullback distance, similarity of species quantity

317 distribution, $\mathrm{pH}$, base saturation, $\mathrm{C} / \mathrm{N}$ ratio), the variance and change levels at

318 the levels of ecological functions or ecosystems are aggregated via the modal

319 value, as in method (1). 
321 To make the application of the classification model more effective for larger

322 amounts of data, the OESI tool can be used as a functional extension of

323 ArcGIS® Desktop 10.2 (Nickel \& Schröder 2017 b). It was implemented using the

324 Python programming language and supports the classification of deviations from

325 the reference state on the basis of 2711 rules for 60 ecosystem types and 6

326 indicators to date: Kullback distance, similarity of species quantity distribution,

$327 \mathrm{pH}$, base saturation, $\mathrm{C} / \mathrm{N}$ ratio and moisture index.

$329 \quad$ 2.2.3 Determination of temporal trends

331 From repeated recordings of the ecosystem condition, temporal trends can be 332 derived and interpreted. This is demonstrated by the example of the ICP Forests

333 Level II programme (Table 10): Site LII-1605 (Großer Eisenberg, Thuringian

334 Forest, Germany); altitude: 851-900 m; ecosystem type: Rohhumus-Fichten-

335 Hochbergwald (C4-6d-B1; Raw-humus spruce forest on the altimontane level) 336 
337 Table 10. Temporal developments of the ecosystem state between 1960 and 3382009 using the example of Level II site 1605 (Großer Eisenberg, Thuringian 339 Forest, Germany)

\section{Habitat function}

\begin{tabular}{|c|c|c|c|c|c|c|c|c|}
\hline & \multicolumn{8}{|c|}{ Kullback distance to the mean species quantity distribution of the type: } \\
\hline 1960 & \multicolumn{3}{|l|}{0.31} & & & & & 4.0 \\
\hline 2001 & $0 \quad 0.52$ & & \multicolumn{2}{|l|}{1.97} & & & & 4.0 \\
\hline \multirow[t]{2}{*}{2006} & $0 \quad 0.52$ & 1.72 & & & & & & 4.0 \\
\hline & \multicolumn{8}{|c|}{ Similarity (\%) with the mean species quantity distribution of the type: } \\
\hline 1960 & 0 & & & & & 65 & 70 & 100 \\
\hline 2001 & 0 & & & 50 & & 65 & & 100 \\
\hline 2006 & 0 & & & & 61 & 65 & & 100 \\
\hline
\end{tabular}

\section{Net primary production}

\begin{tabular}{l|l|l|l|l|l|l|l|l|l}
\hline & \multicolumn{7}{|c}{ Maximum average annual NPP of tree wood compared to type (t TS / ha): } \\
\hline 1995 & & & 1.9 & 2.2 & & & & & \\
\hline 2000 & & & 2.0 & 2.2 & & & & & \\
\hline 2004 & & & 2.0 & 2.2 & & & & & \\
\hline 2009 & & & 2.12 .2 & & & & & \\
\hline
\end{tabular}

\section{Carbon storage}

\begin{tabular}{l|l|l|l|l|l|l|l|l}
\hline & \multicolumn{6}{|c}{ Carbon stock in humus (support and bottom block 0 - $80 \mathrm{~cm}$ depth. $\mathrm{t} / \mathrm{ha}$ ): } \\
\hline 2009 & $\begin{array}{l}85.7 \\
80\end{array}$ & & & & & & \\
\hline
\end{tabular}

\section{Nutrient flow}

\begin{tabular}{l|l|l|l|l|l|l|l|l|l|l|l|l}
\hline & \multicolumn{2}{|l}{$\mathrm{pH}\left(\mathrm{KCl}\right.$ or $\left.\mathrm{CaCl} 2^{*}\right)$ * Measured value Level-II } \\
\hline 1960 & 2.0 & 2.8 & & & & & & & & & & 8.0 \\
\hline
\end{tabular}


16.12.2020 10:45:45

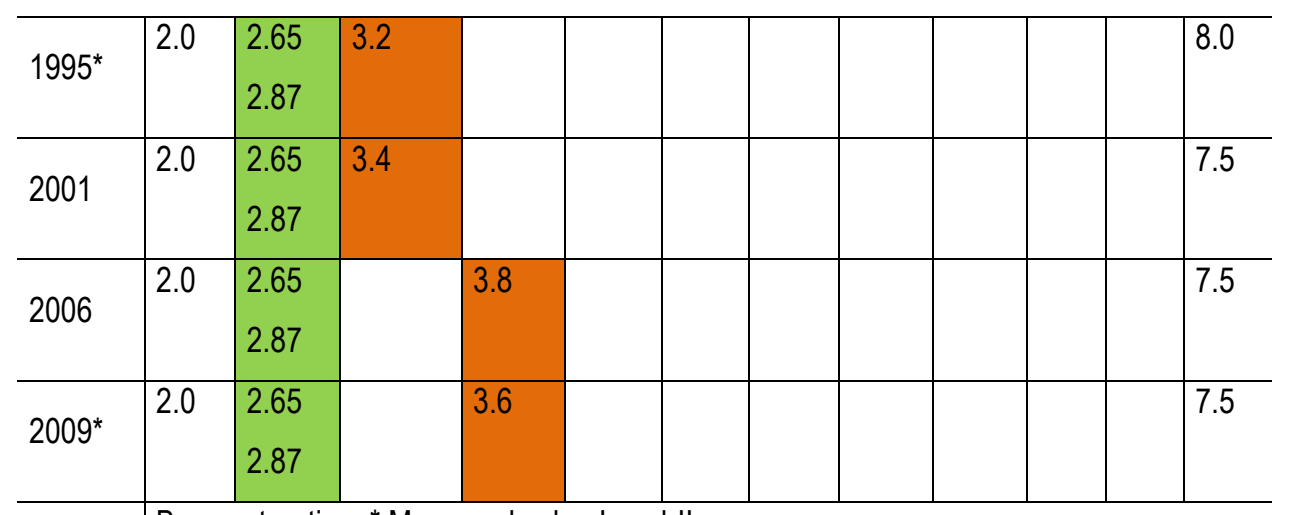

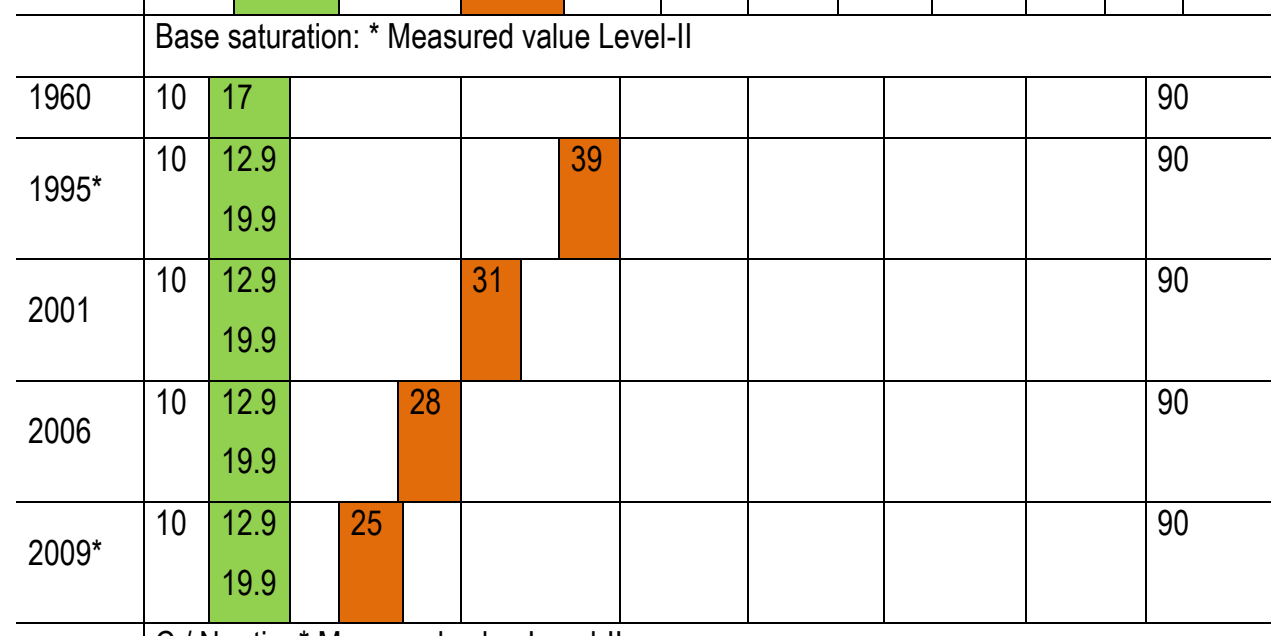

\begin{tabular}{l|l|ll|l|l|l|l}
\hline \multicolumn{6}{|l|}{ C / N ratio: * Measured value Level-I } \\
\hline 1960 & 35 & 29.2 & 27.4 & 26.2 & & & \multicolumn{2}{l}{} \\
\hline $1995^{*}$ & 35 & 29.2 & 26.2 & & & 17.7 & 10 \\
\hline 2001 & 35 & 29.2 & 26.2 & & & 18.3 & 10 \\
\hline 2006 & 35 & 29.2 & 26.2 & & & 17.1 & 10 \\
\hline $2009^{*}$ & 35 & 29.2 & 26.2 & & & 17.4 & 10 \\
\hline
\end{tabular}

Nutritive elements in last year's spruce needles (\%)

(mean values from 9 samples between 1996 and 2009)

\begin{tabular}{l|l|l|l|l|l|l|l|l|l|l|l|l}
\hline $\mathrm{N}$ & 1.0 & & & 1.32 & & 1.52 & & & & & & 2.2 \\
\hline
\end{tabular}




\begin{tabular}{|c|c|c|c|c|c|c|c|c|c|}
\hline & & & & 1.36 & & & & & \\
\hline$P$ & 0.06 & & & & 0.14 & & 0.18 & 0.24 & 0.30 \\
\hline $\mathrm{K}$ & 0.2 & & 0.49 & 0.54 & & & 0.88 & & 1.4 \\
\hline $\mathrm{Ca}$ & 0.2 & 0.36 & & & 0.62 & 0.72 & & & 1.4 \\
\hline $\mathrm{Mg}$ & 0.06 & 0.09 & & 0.13 & & & 0.19 & & 0.30 \\
\hline
\end{tabular}

Water flow

\begin{tabular}{l|l|l|l|l|ll|l|l|l|l|l}
\hline & \multicolumn{2}{|l}{ Moisture index } \\
\hline 1960 & 1 & & & & 5.1 & 5.6 & 6.5 & & & & 10 \\
\hline 2001 & 1 & & & & 5.1 & 6.5 & & & & 10 \\
\hline 2006 & 1 & & & & 5.1 & 6.5 & & & & 10 \\
\hline
\end{tabular}

\section{Adaptation to changing environmental conditions}

\begin{tabular}{l|l|l|l|l|l|l|l|l|l|l}
\hline & \multicolumn{6}{l}{$\begin{array}{l}\text { Similarity (\%) between the quantity distribution of tree species and the spectrum of } \\
\text { natural site tree species: }\end{array}$} \\
\hline 1960 & 0 & & & & & & 60 & & & 95100 \\
\hline 2001 & 0 & & & & & & 60 & & & 95100 \\
\hline 2006 & 0 & & & & & & 60 & & & 95100 \\
\hline
\end{tabular}

340 Explanation: The vegetation survey from 1960 does not originate from the Level II data set, but

341 from the W.I.E. database and was recorded by H. SCHLÜTER. Regarding the year in which the

342 stock was established, there were deviations between the information on the website of the

343 Thuringian State Institute for Forest, hunting and fishing ${ }^{2}$ and the Level II dataset, that could not

344 be fully clarified. For the calculation of net primary production, an age of 80 years in 1995 was

345 assumed on the basis of the latter information. This may explain the low absolute values of the 346 calculated NPP.

2 http://www.thueringen.de/imperia/md/content/folder/waldoekolog/waldzustandsueberwachung/eisenberg09.pdf 
348 Example: ICP Forests Level II site 1605 (Großer Eisenberg, Thuringian Forest,

349 Germany)

350

351 In 1960, the stand matched all ecological parameters of the associated

352 ecosystem type (Rohhumus-Fichten-Hochbergwald). This type corresponds to

353 the natural type of forest that forms in the ridges of the Thuringian Forest under

354 today's climatic conditions in self-organisation.

355

356 The data from 1995 onwards could be attributed to the effect of liming, whereby

357 both the vegetation and the topsoil data point to a decreasing effect until 2009

358 with at least partial reversible development to the original spruce forest type. This

359 becomes particularly clear in the development of base saturation. In vegetation,

360 this effect is reflected in the occurrence of Rubus idaeus and Oxalis acetosella

361 from 2001 and in their decline with simultaneous increases in Trientalis europaea

362 and Deschampsia flexuosa in 2006. The significant narrowing of the $\mathrm{C} / \mathrm{N}$ ratio of

363 the topsoil and the increased $\mathrm{N}$ value in the needles compared to the reference 
364 condition observed since 1995 can be attributed essentially to the increased $\mathrm{N}$ 365 release due to mineralisation of the topsoil due to liming.

367 In fact, at the end of the 1980s, the Institute of Forest Sciences Eberswalde (IFE)

368 developed a method to remedy the Mg deficiency symptoms of the spruce in the

369 Thuringian Forest that had appeared on a large scale at the time (personal

370 communication by Prof. Dr. habil. Gerhard Hofmann, Eberswalde, 12.12.2017).

371 Initially, experiments were carried out on Mg liquid fertilization from the air, which,

372 however, showed no effect due to insufficient quantities. As a result, it was

373 decided to fly large areas of the Thuringian Forest, including the ridges around

374 the Großer Eisenberg, with Kamsdorfer Mg marl (high proportions of $\mathrm{CaCO}_{3}$, $\left.375 \mathrm{MgCO}_{3}\right)$.

376

377 With regard to the assessment of the longer-term effects of liming, it is

378 remarkable that the proportion of basic cations in the spruce needles between

3791995 and 2009 remains well below the reference state. A temporal trend was not

380 detectable in the data. This obviously reflects the effect of nitrous gases, which in 
381 the eighties had led to extensive needle yellowing in the Thuringian Forest. The 382 nutrient disharmonies in the needles induced by the $\mathrm{N}$ effect were not eliminated 383 by the marl fertilization, but were obviously maintained as a result of the 384 increased $\mathrm{N}$ mineralization and $\mathrm{N}$ uptake by the roots. The relative increase in 385 DNP at the time of culmination, calculated from the development of the mean 386 level, indicates accelerated growth due to the enhanced $\mathrm{N}$ input. These cause387 effect relationships indicated here should be further analysed against the 388 background of the process data collected in the EU measurement programme. 389

390 It is clear that with the proven ecological changes compared to the 1960 s, the 391 habitat function protected by the FFH habitat type has been adversely affected.

392 The observed reversible development of vegetation and topsoil condition, on the 393 other hand, is positive.

395 Since the 1960s, the moisture level indicated by the observed vegetation 396 formation has shifted half a degree towards drier condition and is now at the 397 lower interval limit of the reference condition. A further warming to be expected 
398 as a result of climate change could lead to a further decrease in the spread of the 399 natural spruce forest type in the ridges of the Thuringian Forest and a significant 400 expansion of the spectrum of natural site tree species.

401

4023 Discussion

403

404 Since a couple of years there is a broad discussion about sustainable 405 development, ecosystem integrity, ecosystem services and biodiversity in 406 science and public. However, aside from a bunch of definitory treatises, 407 operationalised approaches which are based on indicators quantifying ecosystem 408 functions and structures with data from monitoring programmes of competent 409 authorities are lacking (Roche and Campagne 2017).

410

411 Ecosystem integrity or related notions are referred to in several national and 412 international biodiversity and ecosystem policies. However, it is still poorly 413 defined and operationalised. Based on a broad literature review Roche and 414 Campagne (2017) identified five forms of ecosystem integrity: 1. ecosystem 
415 integrity of wilderness, 2. ecosystem functional and structural integrity, 3. 416 ecosystem stability and resilience, 4. ecosystem condition and 5. ecosystem 417 quality and value. The concept of hemeroby is associated with form 1 proposing 418 that natural state or ahemeroby can be defined by the absence evidence of past 419 and actual human management (Machado 2004). The values of Hemeroby index 420 are determined by the degree of occurrences of human pressures, generally 421 indicated by land use, landscape patterns and species assemblages. Walz and 422 Stein (2014) published a Hemeroby map of Germany linking some few surface 423 covering data: the CORINE land cover datase, the Base-Landscape Model of the 424 Authoritative Topographic-Cartographic Information System and the Digital Land 425 Cover model for Germany. A seven-point scale was used to classify land use by 426 degree of hemeroby. Ecosystem functions were not taken into account, nor were 427 data from ecological environmental monitoring. Following Walz and Stein 428 (2014:2), their hemeroby mapping approach "is inappropriate for a more accurate 429 calculation of spatial extent and thus the monitoring of local and regional 430 developments." Therefore, in our investigation we developed a methodology 431 based on 14 indicators for six ecosystem functions (habitat function, net primary 
432 function, carbon sequestration, nutrient and water flux, resilience) by example of 433 Germany. It allows assessments of ecosystem integrity changes by comparing 434 current or prospective ecosystem states with ecosystem-type specific reference 435 states as described by quantitative indicators for 61 forest ecosystem types 436 based on data before 1990 (Jenssen et al 2019c). Advantages of the rule-based 437 method are the increase in reproducibility and effectiveness in assessments of 438 ecosystem integrity and the coverage of three spatial scale: the forest stand level 439 as well as the regional and national level. As a limitation of the methodology, it 440 should be noted that the use of the mode in the aggregation scheme is 441 associated with a levelling within the range of the ratings. For special issues 442 (e.g., early warning) other linkage algorithms (e.g., maximum) may be more 443 appropriate. Due to the formal classification at the levels of the indicators and 444 ecosystem functions, the evaluation always remains comprehensible in detail. In 445 addition, thresholds derived from the classification can provide orientation for 446 deriving existing needs for action. 
450 A methodological gap in the operationalization of the ecological integrity of 451 forests on the basis of generally available data in Germany was closed by the 452 method presented in this article. Following Roche and Campagne (2017) who 453 identified five major forms of ecosystem integrity concepts, the approach 454 presented operationalises the ecosystem functional and structural integrity. 455 Thereby, the functional and structural indicators were quantified by data from 456 monitoring programmes of competent authorities. Opportunities for the further 457 research are the extension of the methodology to agrarian ecosystems in 458 Germany and forest ecosystems of Europe.

$460 \quad$ List of Abbreviations

$461 \quad A$

Surface soil

462 BfN German Federal agency for nature conservation

$463 \mathrm{Ca}$

Calcium

464 Corg

Organic carbon

465 Cov $\%$

Cover ratio of plant speciec 
$466 \quad d \quad$ Diameter

467 DGZ Average timber growth

468 DKF Soil moisture index

469 DNP Average net primary production

$470 \quad$ ESI Ecosystem integrity

471 EU European Union

472 EUNIS European Nature Information System

$473 \mathrm{~h} \quad$ Tree height

474 HF Habitat function

475 HG Mean stand height

476 ICP International Cooperative Programme

477 K Potassium

$478 \mathrm{KCL} \quad$ Potassium chloride

479 KD Kullback distance

$480 \quad \mathrm{Mg} \quad$ Magnesium

$481 \mathrm{n} \quad$ Sample size

$482 \mathrm{~N} \quad$ Nitrogen 


$\begin{array}{lll}483 & \text { NF } & \text { Nutrient flow } \\ 484 & \text { NPP } & \text { Net primary production } \\ 485 & \text { O } & \text { Organic surface layer } \\ 486 & \text { P } & \text { Phosphorus } \\ 487 & \text { S } & \text { Similarity index } \\ 488 & \text { V } & \text { Base saturation } \\ 489 & \text { WF } & \text { Water flow } \\ 490 & \text { W.I.E. } & \text { Institute of Forestry Eberswalde }\end{array}$

491

492 Declarations

493

494 Ethics approval and consent to participate

$495 \quad$ Not applicable

496

497 Consent for publication

$498 \quad$ Not applicable

499 
500 Availability of data and materials

501 The datasets generated and/or analysed during the current study are cited in the

502 References and are available in the ZENODO repository,

503 https://doi.org/10.5281/zenodo.2606380. Also scientific software generated

504 during the current study is available in the ZENODO repository,

505 https://doi.org/10.5281/zenodo.1319552

506

507 Competing interests

508 The authors declare that they have no competing interests

509

$510 \quad$ Funding

511 Federal Environmental Agency, Dessau-Roßlau, Germany.

512

513 Authors' contributions

514 Winfried Schröder headed the study and drafted the manuscript. Martin Jenssen

515 developed the methodology and performed, together with Stefan Nickel, the

516 computations. 
518 Acknowledgements

519 We would like to thank the Federal Environment Agency (Dessau-Roßlau, 520 Germany) for financial support and professional advice.

521

522 Endnotes

523 Not applicable

524

525 References

526

527 Ellenberg H, Weber HC, Düll R, Wirth V, Werner W, Paulissen D (1992)

528 Zeigerwerte von Pflanzen in Mitteleuropa [Indicator values of plants in Central

529 Europe]. 3. Aufl., Scripta Geobotanica 18:1-258.

530 Hofmann G (1974) Die natürliche Waldvegetation Westthüringens, ihre

531 Gliederung und ihr Weiserwert für Boden, Klima und Ertrag [The natural forest

532 vegetation of West Thuringia, its structure and its indicator values for soil, 
climate and yield]. Institut für Forstwissenschaften Eberswalde. Eberswalde, Akademie der Landwirtschaftswissenschaften der DDR, 536 S. Verbindung mit Niederschlagsarmut. Mit Anlagen [Development of the forest vegetation of the north-eastern lowlands of Germany under the conditions of rising nitrogen inputs in connection with low rainfall. With attachments]. In:

\section{5}

546

Anders S et al (eds) Ökologie und Vegetation der Wälder Nordostdeutschlands [Ecology and Vegetation of the Forests of Northeast Germany]. Dr. Kessel: Oberwinter: 24-41, 201-283 (www.forstbuch.de).

Jenssen M (2010) Modellierung und Kartierung räumlich differenzierter Wirkungen von Stickstoffeinträgen in Ökosysteme im Rahmen der UNECELuftreinhaltekonvention. Teilbericht IIII: Modellierung der Wirkung der Stickstoff-Deposition auf die biologische Vielfalt der Pflanzengesellschaften von Wäldern der gemäßigten Breiten [Modelling and mapping of spatially differentiated effects of nitrogen inputs into ecosystems within the framework of the UNECE Air Pollution Control Convention. Substudy IIII: Modelling of the 
550 effects of nitrogen deposition on the biological diversity of plant communities

551 in temperate forests]. UBA-Texte 09/2010. Dessau-Roßlau.

552 Jenssen M, Hofmann G (2003) Die Quantifizierung ökologischer Potentiale der

553 Phytodiversität und Selbstorganisation der Wälder [The quantification of

554 ecological potentials of phytodiversity and self-organisation of forests].

555 Beiträge zur Forstwirtschaft und Landschaftsökologie 37(1):18-27

556 Jenssen M, Hofmann G (2005) Einfluss atmogener Stickstoffeinträge auf die

557 Vielfalt der Vegetation in Wäldern Nordostdeutschlands [Influence of

558 atmospheric nitrogen deposition on the diversity of vegetation in forests of

559 north-east Germany]. Beiträge zur Forstwirtschaft und Landschaftsökologie

$560 \quad 39(3): 132-141$.

561 Jenssen M, Hofmann G, Nickel S, Pesch R, Riediger J, Schröder W (2013)

562 Bewertungskonzept für die Gefährdung der Ökosystemintegrität durch die

563 Wirkungen des Klimawandels in Kombination mit Stoffeinträgen unter

564 Beachtung von Ökosystemfunktionen und -dienstleistungen [Assessment

565 concept for the threat to ecosystem integrity posed by the effects of climate

566 change in combination with substance inputs, taking into account ecosystem 
567 functions and services]. UBA-Texte 87/2013. Dessau, Textband + 9

568 Anhänge:1-381.

569 Jenssen M, Nickel S, Schröder W (2019 a) 61 Referenzzustände zur Beurteilung

570 der ökologischen Integrität von Wald- und Forstökosystemen, Link zu

571 Forschungsdaten [61 Reference conditions for assessing the ecological

572 integrity of forest and forest ecosystems, link to research data] (Version v1)

573 [Data set]. ZENODO, https://doi.org/10.5281/zenodo.2582888

574 Jenssen M, Nickel S, Schröder W (2019 b) Einstufung der Ökosystemintegrität

575 von Wäldern und Forsten Deutschlands auf Grundlage quantifizierter

$576 \quad$ Indikatoren, Link zu Forschungsdaten und wissenschaftlicher Software

577 [Classification of ecosystem integrity of forests in Germany based on

578 quantified indicators, link to research data and scientific software] (Version v1)

579 [Data set]. ZENODO, https://doi.org/10.5281/zenodo.2606380

580 Jenssen M, Nickel, S, Schröder W (2019 c) Referenzzustände von

581 Ökosystemtypen und Möglichkeiten zusätzlicher biozönotioscher Indikation

582 des ökologischen Bodenzustands als Bestandteil der Ökosystemintegrität

583 [Reference states of ecosystem types and possibilities for additional 
biocoenotic indication of soil ecological status as part of ecosystem integrity] WLN Online-preview: 26 S. (pdf 1.7M; urn:nbn:de:0041-asfv-01831) http://www.afsv.de/index.php/waldoekologie-landschaftsforschung-und-

588 Kullback S (1951) Information theory and statistics. Wiley, New York.

589 Machado A (2004): An index of naturalness. Journal of Nature Conservation $590 \quad 12: 95-110$.

591 Maes J, Teller A, Erhard M, Grizzetti B, Barredo JI, Paracchini ML, Condé S, 592 Somma F, Orgiazzi A, Jones A, Zulian A,Vallecilo S, Petersen JE, Marquardt 593 naturschutz D, Kovacevic V, Abdul Malak D, Marin Al, Czúcz B, Mauri A, Loffler P, Bastrup-Birk A, Biala K, Christiansen T, Werner B (2018) Mapping and assessment of ecosystems and their services: An analytical framework for 597 Mitchell BR, Tierney GL, Schweiger EW, Miller KM, Faber-Langendoen D, Grace 598 JB (2014) Getting the message across: Using ecological integrity to 599 communicate with resource managers. In: Guntenspergen GR (Ed) 

Application of threshold concepts in natural resource decision making: New York, Springer-Verlag, pp. 199-230.

602

603

604

605

606

607

608

609

610

611

612

613

614

615

Nickel S, Schröder W (2017 a) Fuzzy modelling and mapping soil moisture for observed periods and climate scenarios. An alternative for dynamic modelling at the national and regional scale? Annals of Forest Science 74(71):1-15.

Nickel S, Schröder W (2017 b) GIS-integrated rule based model for assessing the integrity of forest ecosystems according to Jenssen. Python-Tool for ArcGIS 10.2 (Version v1). https://doi.org/10.5281/zenodo.1319552.

Nickel S, Schröder W (2018) Ecological soil moisture data across Germany, link to shape files. PANGAEA, https://doi.pangaea.de/10.1594/PANGAEA.891249, Supplement to: Nickel S, Schröder W (2017) Fuzzy modelling and mapping soil moisture for observed periods and climate scenarios. An alternative for dynamic modelling at the national and regional scale? Annals of Forest Science 74(71):1-15.

Nickel S, Schröder W, Jenssen M (2019 a) Maps of current semi-natural forest ecosystem types of Germanyand the Kellerwald National Park (Hesse, 

[https://doi.org/10.1007/s13595-019-0849-4].

618 Nickel S, Schröder W, Völksen B (2019 b) Validating the map of current semi619 natural ecosystem types in Germany and their upscaling using the Kellerwald620 Edersee National Park as an example. Environmental Sciences Europe $621 \quad 31(90): 1-20$.

622 Riecken U, Finck P, Raths U, Schröder E, Ssymank A (2006) Rote Liste der 623 gefährdeten Biotoptypen Deutschlands [Red list of endangered biotope types in Germany]. Naturschutz und Biologische Vielfalt 34:1-318.

625 Roche PK, and Campagne CS (2017) From ecosystem integrity to ecosystem 626 condition: a continuity of concepts supporting different aspects of ecosystem 627 sustainability. Current Opinion in Environmental Sustainability 29:63-68.

628 Schröder W, Nickel S, Jenssen M, Hofmann G, Schlutow A, Nagel H-D, Burkhard 629 B, Dworczyk C, Elsasser P, Lorenz M, Meyerhoff J, Weller P, Altenbrunn K 630 (2019) Anwendung des Bewertungskonzeptes für die Ökosystemintegrität 631 unter Berücksichtigung des Klimawandels in Kombination mit Stoffeinträgen. 632 Abschlussbericht [Application of the assessment concept for ecosystem 

integrity taking into account climate change in combination with substance inputs. Final report]. Bd. 1: Schröder W, Nickel S, Jenssen M, Hofmann G, (2019): Anleitung zur Beurteilung der Integrität von Wald- und Forstökosystemen in Deutschland [Guide to assessing the integrity of forest ecosystems in Germany.]. UBA-Texte 97/2019:1-504. Bd. 2: Schröder W, Nickel S, Jenssen M, Hofmann G. Anleitung zur Beurteilung der Integrität von Wald- und Forstökosystemen in Deutschland [Guidance on assessing the integrity of forest ecosystems in Germany]. UBA-Texte 98/2019:1-344. Bd. 3: Hofmann G. Bestimmungsschlüssel der Wald- und Forstökosystemtypen Deutschlands [Identification key for forest ecosystem types in Germany]. UBA-Texte 99/2019:1-234.

Schröder W, Nickel S, Jenssen M, Riediger J (2015) Methodology to assess and 648 map the potential development of forest ecosystems exposed to climate change and atmospheric nitrogen deposition: a pilot study in Germany. Science of the Total Environment 521-52: 108-122.

Ssymank A, Hauke U, Rückriem C, Schröder E (1998) Das europäische Schutzgebietssystem Natura 2000. BfN-Handbuch zur Umsetzung der Fauna- 
650 Flora-Habitat-Richtlinie und der Vogelschutz-Richtlinie [The European system 651 of protected areas Natura 2000. BfN manual for the implementation of the 652 Fauna-Flora-Habitat Directive and the Birds Directive]. Bonn: Bundesamt 653 Naturschutz, Schriftenreihe für Landschaftspflege und Naturschutz 53.560 p. 654 Steinhardt U, Herzog F, Lausch A, Müller E, Lehmann S (1999). The hemeroby 655 index for landscape monitoring and evaluation. In Hyatt DE, Lenz R, Pykh YA 656 (Eds.) Environmental indices systems analysis approach. Advances in 657 sustainable development. Proceedings of the first international conference on 658 environmental indices systems analysis approach (INDEX-97), St.

659 Petersburg, Russia, July 7-11, 1997. EOLSS, Oxford:237-254.

660 Walz U, Stein C (2014) Indicators of hemeroby for the monitoring of landscapes 661 in Germany. Journal for Nature Conservation 22:279-289, $662 \quad$ http://dx.doi.org/10.1016/j.jnc.2014.01.007 663 664 Figure titles and legends 665 
666 Figure 1. Basic scheme for determining the indicators of the habitat function of a 667 current ecosystem type

668 Figure 2. Basic scheme for determining the mean net primary production (NPP)

669 Figure 3. Basic scheme for determining the $\mathrm{C}_{\text {org }}$ content in humus

670 Figure 4. Basic scheme for the determination of indicators of water and nutrient 671 flow

672 Figure 5. Basic scheme for determining the similarity of the current tree species

673 composition with the spectrum of natural tree species

674 Figure 6. Scheme for classifying ecosystem integrity

675 Figure 7. Classification of ecosystem integrity and derivation of needs for action 676 (based on Mitchell et al. 2014)

677 Figure 8. Ecosystem integrity assessment sheet for a Raw-humus spruce forest 678 on the altimontane level (C4-6d-B1), ICP Forests Level II site 1605 (Großer 679 Eisenberg, Thuringian Forest, Germany)

680 Figure 9. Ecosystem type-specific classifications of deviations from the reference 681 condition for the moisture index in the Kellerwald-Edersee National Park (Hesse, 682 federal state of Germany) 
16.12.2020 10:45:45

683 Figure 10. Grid-based classifications of the deviations from the reference state 684 for the soil moisture index in the Kellerwald-Edersee National Park (Hesse, 685 federal state of Germany) 


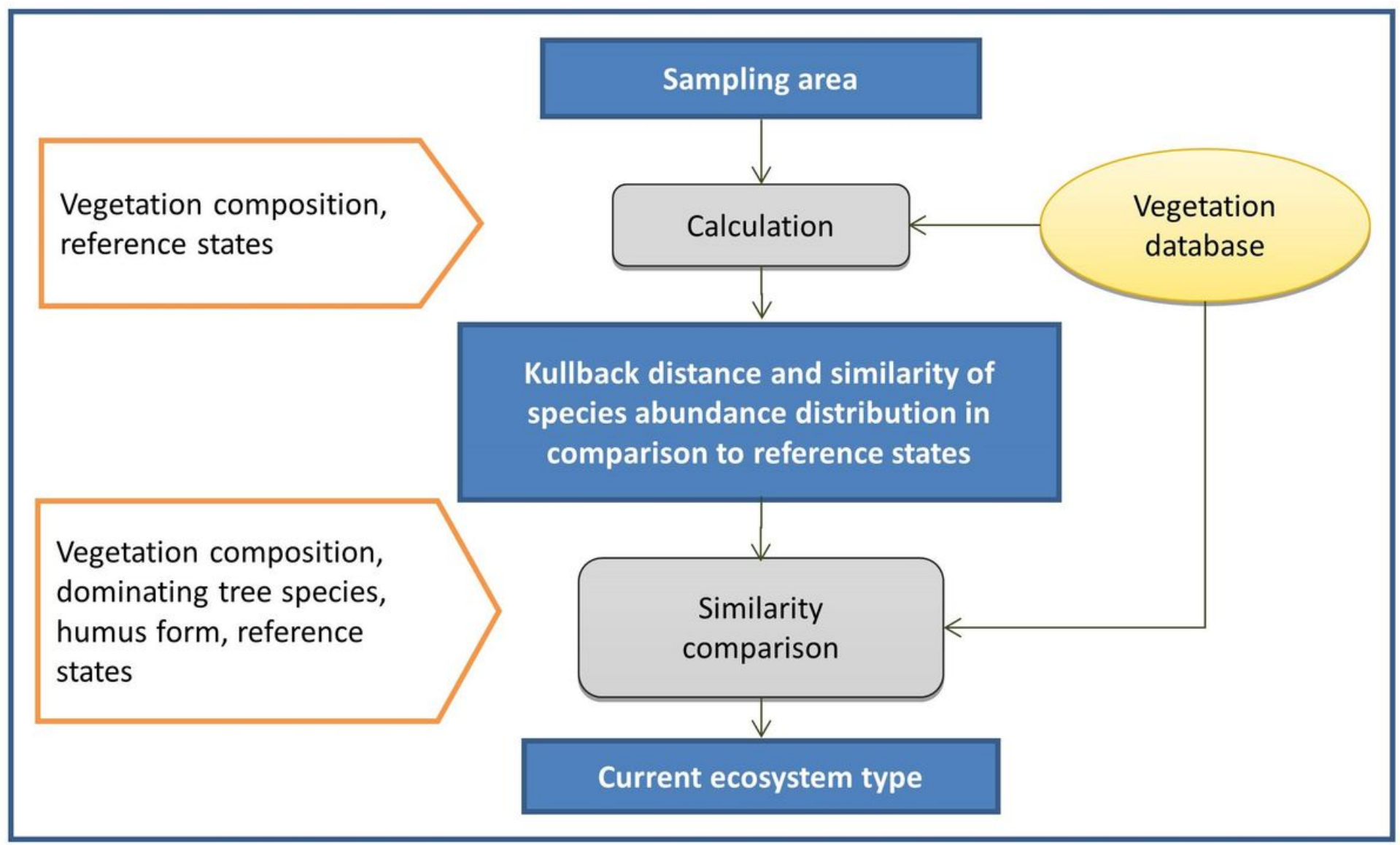

Figure 1

Basic scheme for determining the indicators of the habitat function of a current ecosystem type 


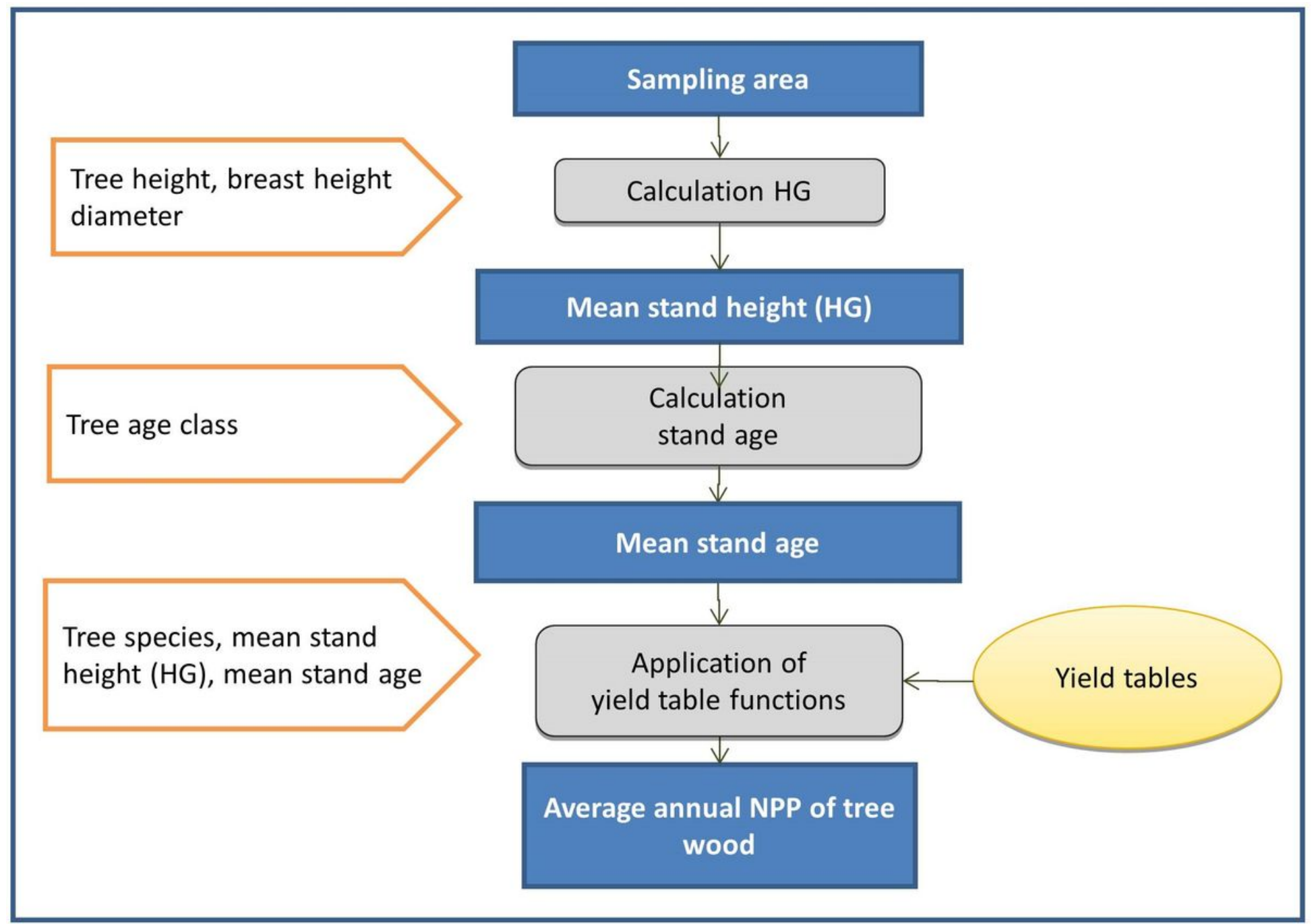

\section{Figure 2}

Basic scheme for determining the mean net primary production (NPP)

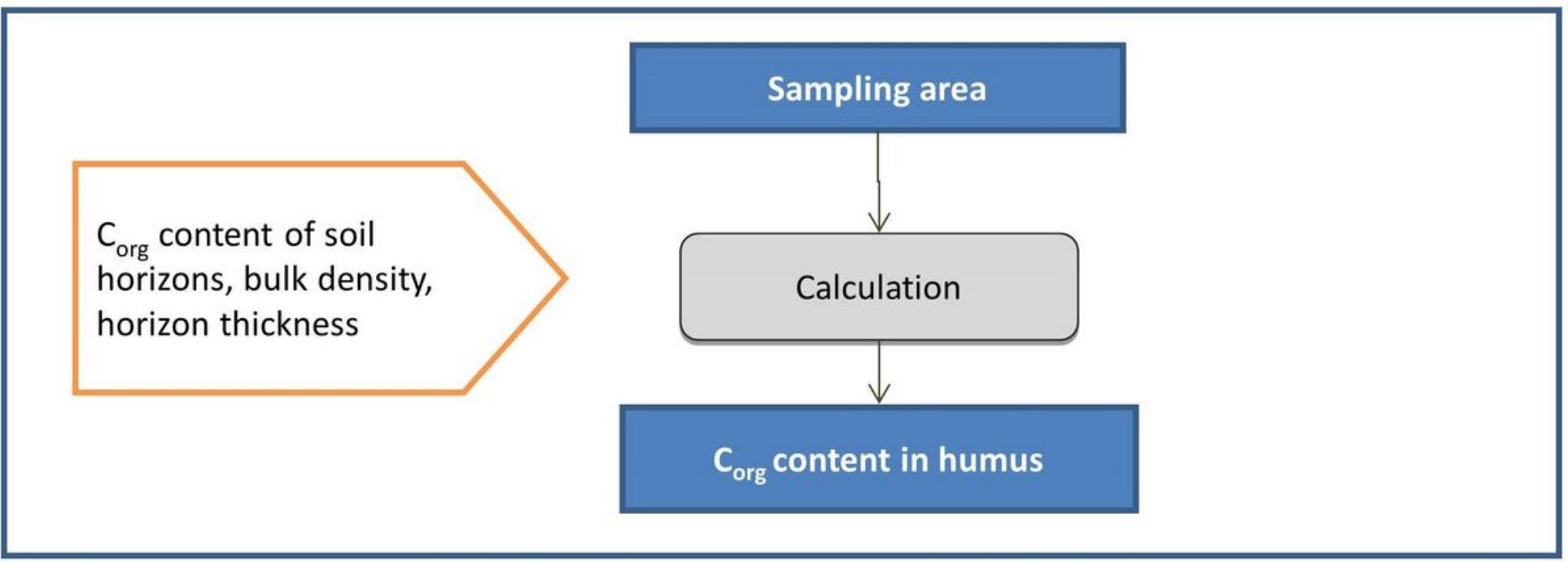

Figure 3 
Basic scheme for determining the Corg content in humus

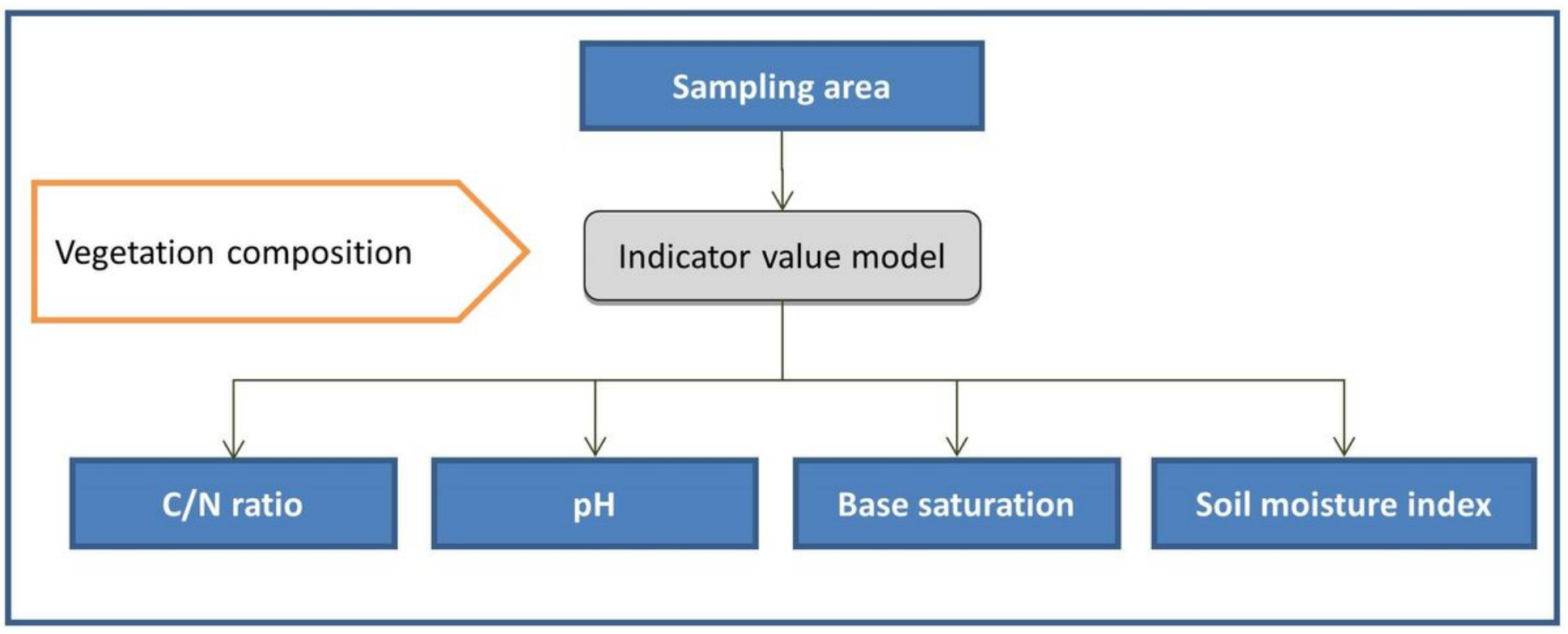

Figure 4

Basic scheme for the determination of indicators of water and nutrient flow

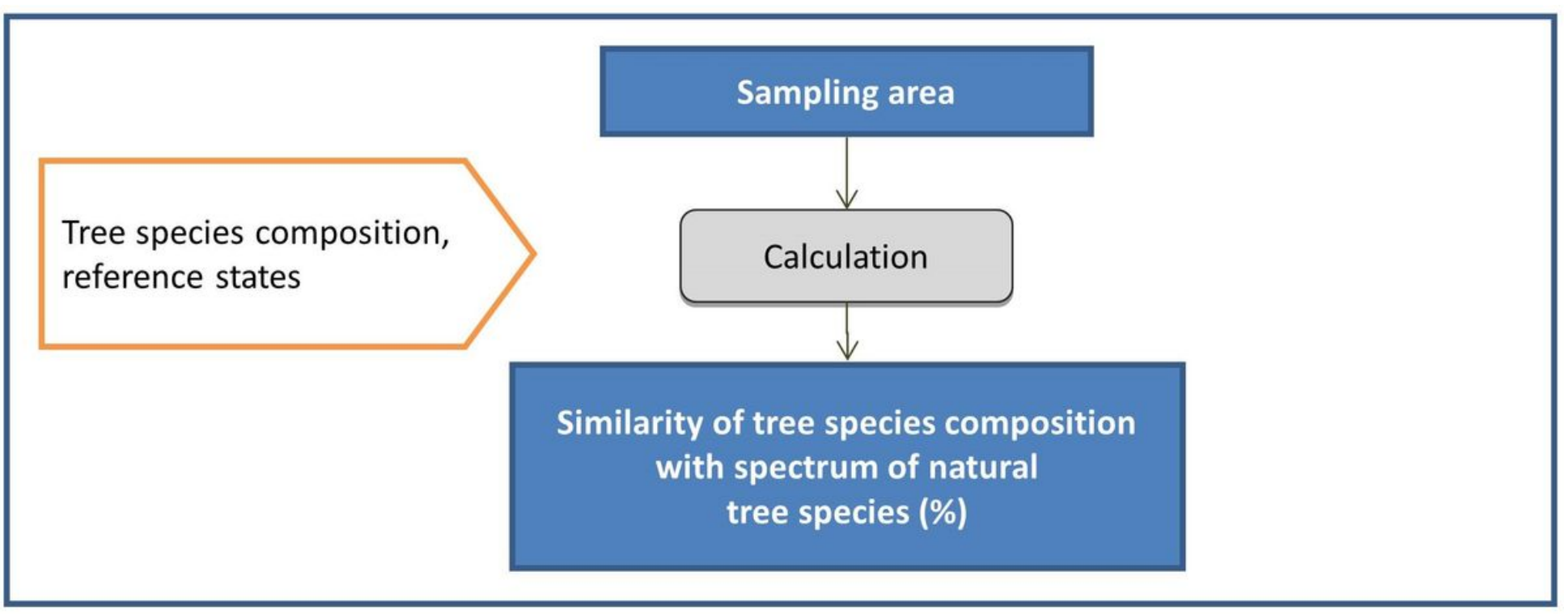

\section{Figure 5}

Basic scheme for determining the similarity of the current tree species composition with the spectrum of natural tree species 


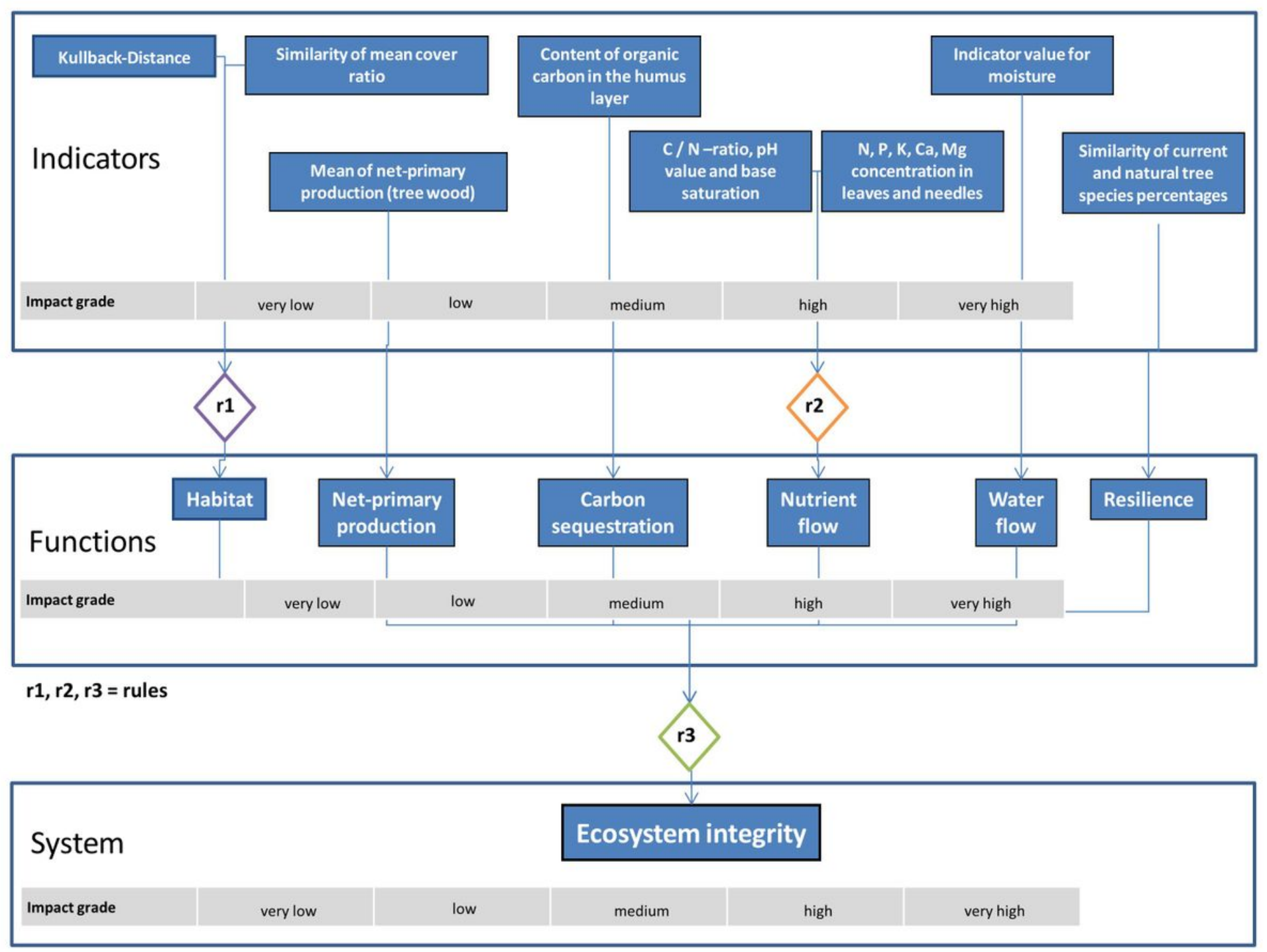

\section{Figure 6}

Scheme for classifying ecosystem integrity 


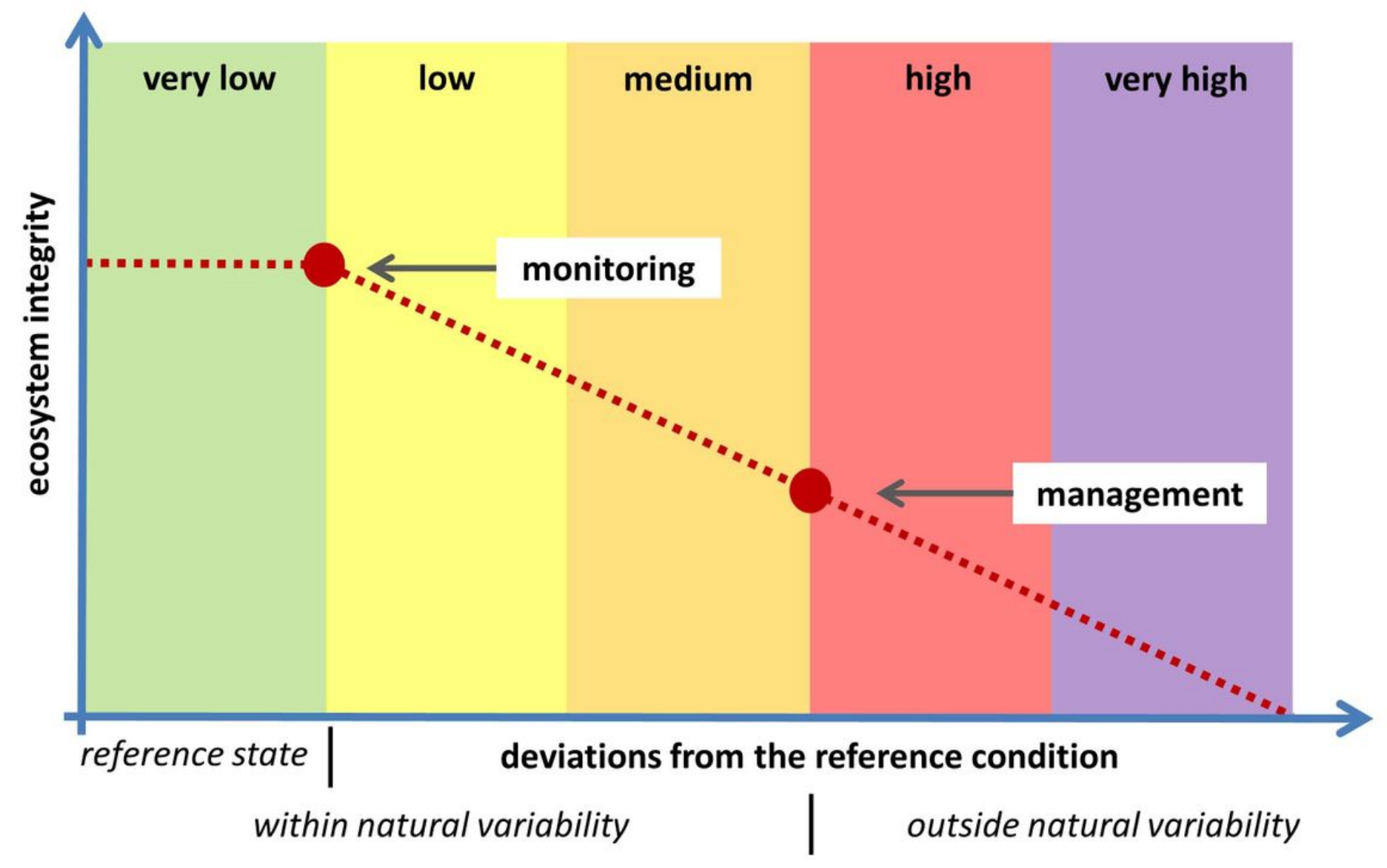

Figure 7

Classification of ecosystem integrity and derivation of needs for action (based on Mitchell et al. 2014) 


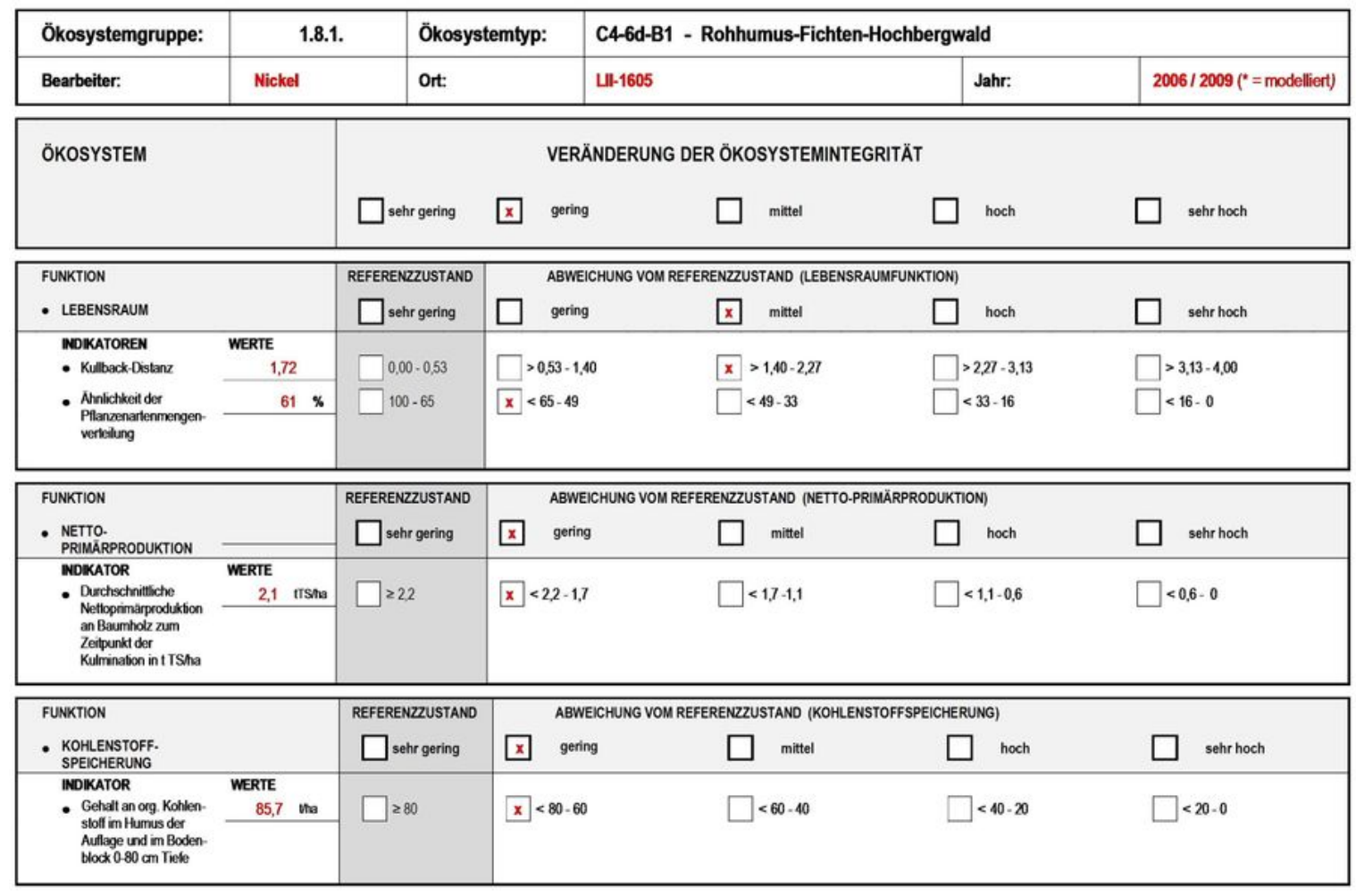

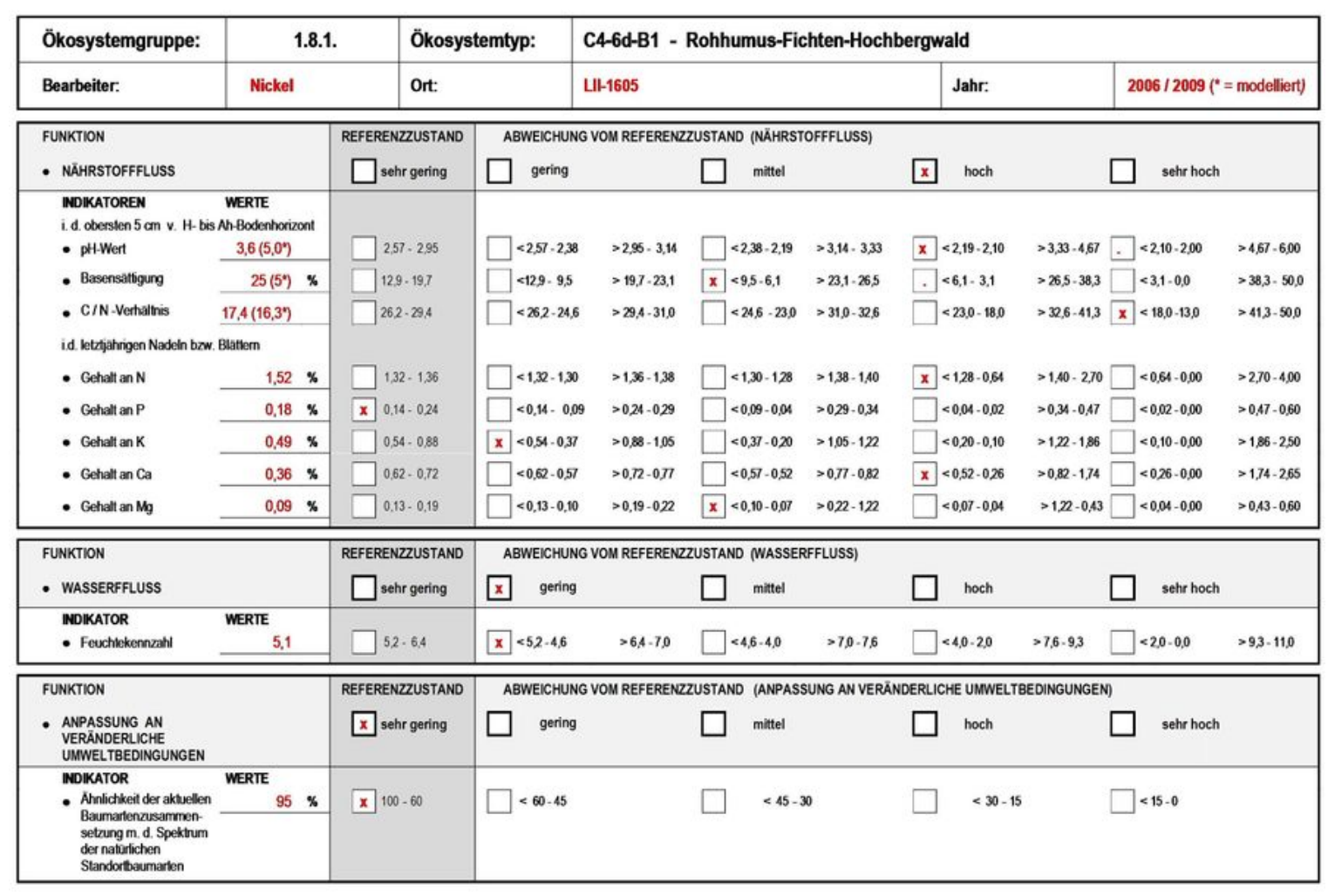

\section{Figure 8}

Ecosystem integrity assessment sheet for a Raw-humus spruce forest on the altimontane level (C4-6dB1), ICP Forests Level II site 1605 (Großer Eisenberg, Thuringian Forest, Germany) 


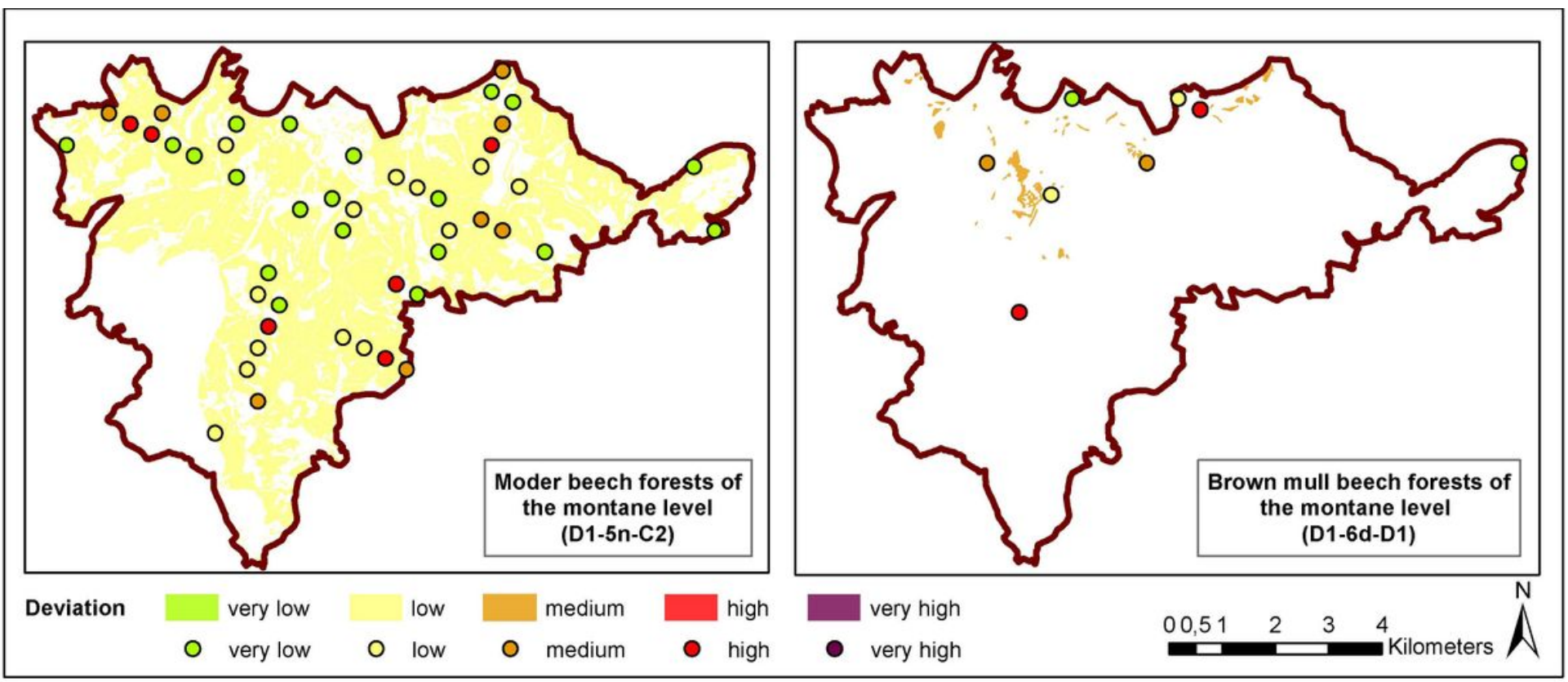

Figure 9

Ecosystem type-specific classifications of deviations from the reference condition for the moisture index in the Kellerwald-Edersee National Park (Hesse, federal state of Germany)

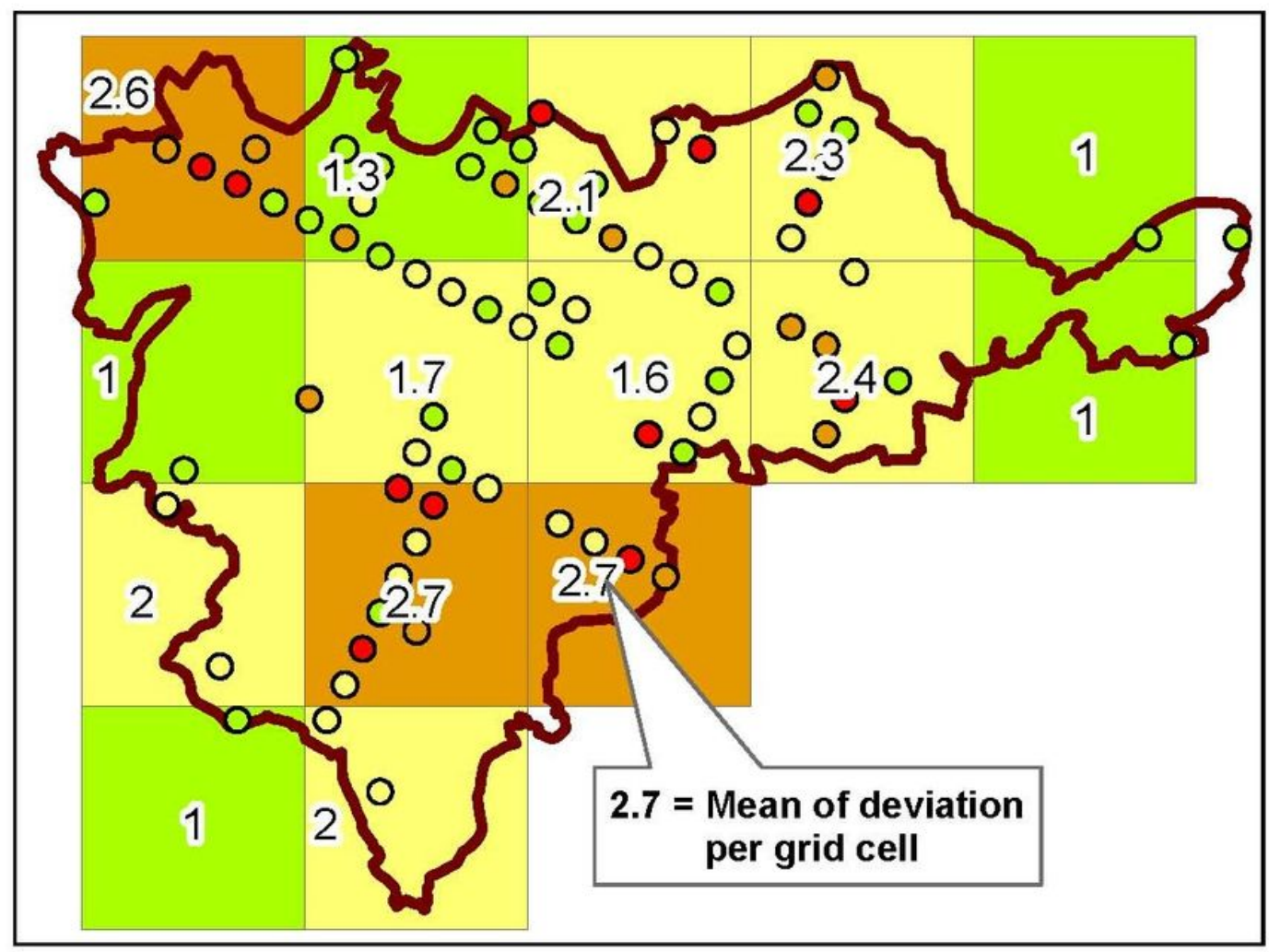

\section{Soil moisture index}

Deviation

\begin{tabular}{|c|c|c|}
\hline & very low & \\
\hline & low & \\
\hline & medium & \\
\hline & high & \\
\hline & very high & \\
\hline 0 & very low & \\
\hline 0 & low & \\
\hline 0 & medium & \\
\hline 0 & high & \\
\hline ○ & very high & \\
\hline 0.51 & 12 & 3 \\
\hline
\end{tabular}

Figure 10 
Grid-based classifications of the deviations from the reference state for the soil moisture index in the Kellerwald-Edersee National Park (Hesse, federal state of Germany) 